\title{
Modelling and experimental verification of a solar-powered liquid desiccant cooling system for greenhouse food production in hot climates
}

\author{
G. Lychnos and P. A. Davies* \\ Sustainable Environment Research Group, School of Engineering and Applied \\ Science, Aston University, Birmingham, UK \\ *corresponding author: Tel +44 121204 3724, e-mail: p.a.davies@aston.ac.uk
}

\begin{abstract}
Experiments and theoretical modelling have been carried out to predict the performance of a solar-powered liquid desiccant cooling system for greenhouses. We have tested two components of the system in the laboratory using $\mathrm{MgCl}_{2}$ desiccant: (i) a regenerator which was tested under a solar simulator and (ii) a desiccator which was installed in a test duct. Theoretical models have been developed for both regenerator and desiccator and gave good agreement with the experiments. The verified computer model is used to predict the performance of the whole system during the hot summer months in Mumbai, Chittagong, Muscat, Messina and Havana. Taking examples of temperate, subtropical, tropical and heat-tolerant tropical crops (lettuce, soya bean, tomato and cucumber respectively) we estimate the extensions in growing seasons enabled by the system. Compared to conventional evaporative cooling, the desiccant system lowers average daily maximum temperatures in the hot season by $5.5-7.5^{\circ} \mathrm{C}$, sufficient to maintain viable growing conditions for lettuce throughout the year. In the case of tomato, cucumber and soya bean the system enables optimal cultivation through most summer months. It is concluded that the concept is technically viable and deserves testing by means of a pilot installation at an appropriate location.
\end{abstract}

Key Words: solar energy; liquid desiccant cooling; greenhouse; climate change; food security. 
Notation

\section{List of symbols}

$A_{1}$

$A_{2}$

A

$a$

$C_{\text {pa }}$

$h_{\mathrm{fg}}$

$I_{\mathrm{R}}$

$K_{\mathrm{c}}$

$\dot{m}_{a}$

$\dot{m}_{a b s}$

$\dot{m}_{e v}$

$T_{\mathrm{a}}$

$T_{\text {amb }}$

$T_{\text {amb,wb }}$

$T_{\mathrm{gh}}$

$T_{\mathrm{w}}$

$\dot{V}_{a}$

W

$x$

X

Greek variables$$
\gamma
$$$$
\eta
$$

$\rho_{a}$

$\tau$

$\omega$

\section{Units}

$\mathrm{K} \mathrm{m}^{-1}$

$\mathrm{m}^{-1}$

$\mathrm{m}^{2}$

$-$

$\mathrm{J} \mathrm{kg}^{-1} \mathrm{~K}^{-1}$

$\mathrm{J} \mathrm{kg}^{-1}$

$\mathrm{W} \mathrm{m}^{-2}$

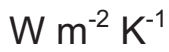

$\mathrm{kg} \mathrm{s}^{-1}$

$\mathrm{kg} \mathrm{s}^{-1}$

$\mathrm{kg} \mathrm{s}^{-1}$

${ }^{\circ} \mathrm{C}$

${ }^{\circ} \mathrm{C}$

${ }^{\circ} \mathrm{C}$

${ }^{\circ} \mathrm{C}$

${ }^{\circ} \mathrm{C}$

$\mathrm{m}^{3} \mathrm{~s}^{-1}$

m

$\mathrm{m}$

$\mathrm{kg} \mathrm{kg}^{-1}$

\section{Definition}

parameter

parameter

regenerator surface area

absorptivity

specific heat capacity of air

latent heat of evaporation

solar irradiance

Overall heat loss coefficient of greenhouse cover air mass flow rate

water rate of absorption

rate of evaporation

air temperature

ambient temperature

ambient wet bulb temperature

temperature inside greenhouse temperature of cooling water

ventilation rate

width of greenhouse

distance from inlet

mass concentration plant transpiration coefficient

effectiveness

$\mathrm{kg} \mathrm{m}^{-3} \quad$ absolute density of air

transmissivity of greenhouse roof

absolute humidity

Abbreviations: $\quad$ EvCool - evaporative cooling

LDCS - liquid desiccant cooling system

NTU - number of transfer units

$\mathrm{RH}$ - relative humidity 


\section{Introduction}

Energy is closely linked to food. In the US, for example, food production and processing accounted for $15.7 \%$ of the total energy consumption in 2007 [1]. In addition, the use of energy resources from fossil fuels is a major contributor to climate change which is likely to hinder agriculture and threaten food security in the future. In its fourth assessment report, the Intergovernmental Panel on Climate Change (IPCC) noted that temperature increases of just 1 to $2{ }^{\circ} \mathrm{C}$ would be sufficient to reduce crop productivity in low latitudes, especially in regions subject to seasonally dry or tropical climates [2]. Moreover, the low latitudes are home to many developing nations whose populations are expected to grow by some $70 \%$ by 2100 [3]. The combination of climate change and increasing food demand make it very important to research intensive means of growing food that can help adapt to warming conditions. Technologies that can achieve this using only renewable energy inputs are especially interesting.

One approach that could aid adaptation to climate change is the provision of artificially cooled environments for the cultivation of crops. The use of greenhouses to provide protected growing environments is increasing around the world. Some greenhouses are cooled using evaporative cooling (pad and fan) or fogging systems. These systems are limited, however, with regard to the lowering of temperature achievable.

A previous study put forward a concept for an enhanced greenhouse system making use of solar energy and liquid desiccant [4]. Desiccant cooling is a well established refrigeration method though more commonly realised with solid rather than liquid desiccants. The latter have the advantage of allowing larger amounts of air to be handled. In addition, it is possible to move the liquid desiccant to a solar regenerator by pumping. Therefore, liquid desiccants are particularly interesting for solar applications requiring large amounts of low-grade cooling.

The earliest reported experiments with liquid desiccant cooling were those of Baum et al. [5] and Kakabaev et al. [6] based on the theoretical work of Kakabaev and Khandurdyev [7]. Since then research has focused on the investigation of the performance of the regenerator and the desiccator, essential components of any liquid desiccant cooling systems (LDCS). Several authors investigated the various types of solar liquid regenerator by performing experiments [8-13] while others investigated the different types of structures used in desiccators [14-28]. Liquid desiccant cooling technology has been investigated extensively for applications such as cooling of human dwellings, commercial buildings and hospitals [29-32]. The chemical compounds used as desiccants are lithium salts $(\mathrm{LiCl}, \mathrm{LiBr})$, calcium chloride or mixtures of $\mathrm{LiCl}, \mathrm{CaCl}_{2}$ and triethylene glycol.

However, some of the above compounds are expensive, scarce or toxic. It has been shown that magnesium chloride $\left(\mathrm{MgCl}_{2}\right)$ is an interesting non-toxic compound for use in greenhouse cooling applications especially for installations near the sea coast [33]. Magnesium chloride is the second most abundant salt in seawater and is the principal constituent of bitterns, the supernatant brine that is a by-product from solar salt works. Seawater bitterns have properties similar to those of pure solutions of magnesium chloride and so they have potential as liquid desiccants [34].

Thus, though a number of authors have investigated solar-powered liquid desiccant cooling systems, so far very few have focussed on the greenhouse application or on the use of $\mathrm{MgCl}_{2}$ as the desiccant. The aim of the current study is to investigate the technical feasibility of these ideas with the help of experiments and modelling. The specific objectives are: (i) to build and test prototypes of the regenerator and desiccator in the laboratory; (ii) to compare the results with the predictions of theories based on studies from the literature that used other liquid 
desiccants; (iii) using a computer model based on the theory, to predict the performance of the cooled greenhouse at large scale in a range of hot climates represented by some coastal cities (Mumbai, Chittagong, Muscat, Messina, Sfax and Havana); and (iv) thus reach conclusions about what is technically possible with the system with regard to lowering of temperatures and the extensions of the growing seasons of typical crops. In contrast to the earlier preliminary study [4], this work takes into account the properties of a specific liquid desiccant $\left(\mathrm{MgCl}_{2}\right)$. In addition, it includes experimental verifications carried out in the laboratory, and detailed modelling of mass and heat transfer enabling the sizing of the main components to be calculated.

\section{Theory}

This section introduces the system and its components and describes the theory that has been used to model each component and thus provide the basis for the predictive model.

\subsection{System concept}

The concept of the cooled greenhouse system is shown schematically in Fig 1 . The essential parts of the system are the regenerator, the desiccator, and the greenhouse including the evaporative pad. There are three process fluids: air, liquid desiccant and cooling water. The desiccator and evaporative pad are both wetted porous media, permeable to air. Atmospheric air enters the system through the desiccator where it is dehumidified as it comes in contact with the liquid desiccant. The lowered humidity means that the cooling effect of the evaporative pad downstream is enhanced. As a result of absorbing water from the air, the liquid desiccant becomes less concentrated. The solar regenerator provides the necessary latent heat to drive off water from the liquid desiccant and thus restore its concentration and desiccant property. The solar regenerator may be placed on the greenhouse roof or on the ground. After leaving the regenerator, the concentrated desiccant is returned to the desiccant pad. To remove the latent heat of condensation and the heat of dilution of the liquid desiccant, the desiccant pad includes cooling tubes carrying cooling water provided at the ambient wet bulb temperature. This cooling water may be supplied from the sea or from a cooling tower. The air is drawn through the system by an exhaust fan.

\subsection{Regenerator}

The regenerator is of open type, consisting of a tilted black surface exposed to the sun with desiccant solution running over it. This is the simplest and cheapest arrangement and therefore considered potentially interesting for the greenhouse application where large areas will be required. Following a survey of theories that have been presented in the literature [5, 7-13, 35-49], it was decided to adopt the theory of Collier [35] which has already been applied successfully by other researchers $[7,11,50]$. This approach applies heat and mass balance to a differential control volume at some position $x$ from the inlet of the regenerator to formulate an ordinary differential equation, the solution to which gives an expression for the rate of evaporation per unit area of the surface. The regenerator theory is presented in detail in Appendix A and reference [51]. 


\subsection{Desiccator}

Fig. 2 shows the detailed arrangement of the desiccator which contains several sections of porous medium (CELdek®) each inserted between bundles of cooling tubes. Based on the relevant inputs (ie. conditions and flow rates of the inlet air, liquid desiccant and cooling water) the theoretical model predicts the mass flux of water absorption and the properties of the fluids at the outlet. The approach is based on the work of Liu and associates [21-23, 52] and that of Khan [53, 54]. It makes use of a computational model which the divides the desiccator into finite control volumes (Fig. 2b). The following assumptions are made:

1. The desiccator operates under steady state conditions and heat losses to the surroundings are negligible.

2. The properties of air change in the $y$ direction only (see Fig. 2b).

3. The properties of the desiccant solution change in the $x$ direction only (see Fig. 2b).

4. The specific heat capacities of air and desiccant solution are considered constant inside each finite control volume.

5. The liquid desiccant is perfectly mixed and uniformly distributed to each finite control volume. The same is true of the air.

To calculate the heat and mass transfer coefficients at the surface of the liquid desiccant, the model uses widely used correlations for Nusselt and Sherwood numbers developed specifically for CELdek® Although the adopted correlations were originally developed for a desiccator that utilised $\mathrm{LiCl}$, in principle they are applicable to other liquid desiccants - including $\mathrm{MgCl}_{2}$ - by use of the appropriate constants and solution properties. To achieve this general applicability, Chung et al. [16] formulated dimensionless groups (i.e. ratio of liquid and mass flow rates, Prandtl and Reynolds numbers, packing volume and size, mass fraction of the desiccant in solution) on the basis of the Buckingham Pi theorem.

Appendix $\mathrm{B}$ details the governing equations used in our model. These equations are applied to each finite control volume using a one-dimensional analysis, thus enabling simplification and integration of the differential equations.

The heat and mass transfer occurring at the cooling tubes needs to take into account heat transfer to the cooling water flowing inside the tubes. Therefore a different model was developed based on the effectiveness-NTU method assuming that the properties of water change only in the $z$ direction. This finite volume model for the cooling tubes is also presented in Appendix B. This approach requires iterations in order to compute the water temperature at the outlet of the cooling tubes. Therefore, a simple iterative scheme is employed to solve the equations for the first section. When the outlet values of the first section are obtained, a second iterative procedure starts for the second section and when a solution is obtained (convergence criterion $0.5 \%$ ) the computer program (implemented in gPROMS®) continues to the next section and so on until the last section. For each finite control volume, local properties and coefficients of heat and mass transfer are used. A wetting factor (the ratio of wetted surface area per volume) is used to account for imperfect wetting due to channelling flow patterns observed in pilot experiments. 


\subsection{Greenhouse and evaporative pad}

The theory used here was developed by Kittas [55] who obtained a high correlation coefficient $\left(R^{2}=91 \%\right)$ between theory and experiments with an operational greenhouse using evaporative pads. The model can therefore predict the temperature inside a cooled greenhouse.

As the air travels through the greenhouse, it becomes hotter. The temperature $T_{\mathrm{gh}}$ at position $x$ from the inlet is given by the following equation

$$
T_{\mathrm{gh}}(x)=T_{\mathrm{amb}}+\left[-\eta \cdot\left(T_{\mathrm{amb}}-T_{\mathrm{amb}, \mathrm{wb}}\right)-\frac{A_{1}}{A_{2}}\right] \cdot \exp \left(-A_{2} \cdot x\right)+\frac{A_{1}}{A_{2}}
$$

where $A_{1}$ and $A_{2}$ are coefficients determined by

$$
A_{1}=\frac{\tau \cdot(1-\gamma) \cdot I_{R} \cdot W}{\dot{V}_{a} \cdot \rho_{a} \cdot C_{p a}}
$$

and

$$
A_{2}=\frac{K_{c} \cdot W}{\dot{V}_{a} \cdot \rho_{a} \cdot C_{p a}}
$$

$\eta$ is the cooling pad effectiveness taken to be $0.8, x$ is the distance from the inlet of the greenhouse (see Fig.1), $K_{\mathrm{c}}$ is the coefficient of heat loss from the greenhouse cover, $\tau$ is the plastic roof transmissivity assumed equal to $0.60, \gamma$ is the plant transpiration coefficient equal to $0.45, \dot{V}_{a}$ is the ventilation rate, $T_{\mathrm{amb}, \mathrm{wb}}$ is the wet bulb ambient temperature and $W$ is the width of the greenhouse. The evaporative cooling pad was assumed to have an effectiveness of 0.8 based also on reference [55]. These equations were used to predict the temperatures at the outlet of the greenhouse, where temperatures were highest, as this represented the worst case as regards the performance of the cooling system.

For all components of the system, the properties of humid air and $\mathrm{MgCl}_{2}$ solution were determined using published formulae or by polynomial equations based on experimental data found in the literature [56-60].

\section{Experiments}

This section describes the materials and methods of experiments carried out in the laboratory with the regenerator and the desiccator.

\subsection{Regenerator}

The experimental regenerator, shown in Fig.3, consisted of a flat rectangular plate inclined at $2.5^{\circ}$ to the horizontal and measured $0.73 \mathrm{~m}$ long in the direction of flow, by $0.84 \mathrm{~m}$ wide, giving an active area of $0.61 \mathrm{~m}^{2}$. Its surface consisted of a $6 \mathrm{~mm}$-thick black neoprene foam sheet providing thermal insulation, covered by a woven black mulch sheet for better spreading of the solution over the surface. Magnesium chloride solution (ie. liquid desiccant) was pumped to a polythene distribution pile at the top of the regenerator. This pipe extended over the width of the regenerator with 21 holes of $2 \mathrm{~mm}$ diameter spaced at $30 \mathrm{~mm}$ intervals.

At the regenerator outlet, the concentrated solution was collected in a rectangular transparent plastic tank. A height gauge enabled the volume of solution in the tank to be measured; thus the mass of evaporated water could be determined with an accuracy of $\pm 14 \mathrm{~g}$. 
To simulate sunlight, an array of 90 daylight simulation bulbs (50 W) was arranged in a triangular pattern with pitch $109 \mathrm{~mm}$. Translucent paper was used to diffuse the light of the lamps and hence achieve better distribution of light at the surface of the regenerator giving a coefficient of variation of $9 \%$. The array of lamps was supported on a horizontal frame. A pyranometer (Kipp \& Zonen CMP 11) was used to measure the irradiance at the regenerator surface which was varied by changing the height of the lamp array.

The solution and ambient air temperatures were measured using platinum resistance detectors (PT100 $\pm 0.03{ }^{\circ} \mathrm{C} @ 0{ }^{\circ} \mathrm{C}$ ) connected to a PC which recorded readings every $1 \mathrm{~s}$. The regenerator surface temperature was measured in 9 positions using an infrared digital thermometer with an accuracy of $\pm 2 \%$. The positions of the temperature measurements can be seen in Fig.3.

To monitor the concentration throughout the regeneration process, samples of the $\mathrm{MgCl}_{2}$ solution were taken from the tank at predefined time intervals. This was achieved by measurement of the refractive index using a refractometer $( \pm 0.00004$ $\mathrm{RI})$ from which concentration was found by means of published tables [61]. The relative humidity and ambient temperature in the laboratory were not controllable but they were monitored (using a Testo 400 probe) and varied within a range of 27$38.5 \% \mathrm{RH}$ and $19-26{ }^{\circ} \mathrm{C}$ respectively.

The volumetric flow remained constant during each experiment and was measured at the outlet using a volumetric cylinder and a stop watch, giving an error of $\pm 1.3 \%$. Each experiment was continued until the system reached steady state condition, i.e. when a constant evaporation rate was achieved, or until crystallisation started to occur. Thus the experiments lasted for between 180 and 525 minutes.

The effectiveness of the regenerator was calculated as the ratio of the latent heat needed to evaporate water from the solution to the absorbed solar energy.

$\eta=\frac{\dot{m}_{\mathrm{ev}} \cdot h_{\mathrm{fg}}}{I_{\mathrm{R}} \cdot a \cdot A} \cdot 100 \%$

Four different series of experiments were carried out at irradiance levels of $I_{R}=400,600,760$ and $970 \mathrm{~W} \mathrm{~m}^{-2}$. Each series consisted of three experiments, each at different solution mass flows per regenerator area of: $0.0033,0.0064$ and $0.0104 \mathrm{~kg}$ $\mathrm{s}^{-1} \mathrm{~m}^{-2}$. The initial concentration of the $\mathrm{MgCl}_{2}$ solution varied in a small range of $0.293-0.334 \mathrm{~kg}$ of solute / $\mathrm{kg}$ of solution corresponding to $40.8-53.4 \%$ equilibrium relative humidity of air brought into contact with it.

\subsection{Desiccator}

The experimental desiccator (Fig.2) was constructed with four sections of porous medium each one sized $0.1 \times 0.1 \times 0.3 \mathrm{~m}$. Each section consisted of specially impregnated and corrugated cellulose paper sheets with different flute angles, one steep $\left(60^{\circ}\right)$ and one flat $\left(30^{\circ}\right)$ that have been bonded together (CELdek® 7090-15). The sections were inserted among 5 banks of cooling tubes, each having 10 copper tubes (15mm outside diameter) carrying tap water. The strong $\mathrm{MgCl}_{2}$ solution entered through two manifolds at the top and flowed downward through the desiccator under gravity thus wetting the porous medium. A tank at the bottom was used to collect the magnesium chloride solution which flowed through a tube to the regenerator as described above. The more concentrated solution flowing out of the regenerator was collected in a tank from where the peristaltic pump returned it to the inlet of the desiccator. The desiccator was fitted inside an insulated duct. Two air sampling tubes for measuring the dry-and wet-bulb temperatures of the incoming humid air and the outgoing dehumidified air were attached to the duct. For this 
purpose a fan (60mm diameter) was fitted inside each sampling tube that drew air out of the rig and recycled it back to the duct; a pair of platinum resistance temperature detectors (PT100) was placed at the fan inlet of each tube. One of each pair was covered with a wick which was kept wet by immersing its end in water. Similar detectors were also used for measuring the solution temperature and the cooling water temperature at the inlet and the outlet of the desiccator.

Before entering the duct, the process air was heated and humidified before by an environmental chamber that allowed the automatic control of the heat and water vapour supply to the air stream. The air passed horizontally through the desiccator ie. in cross flow configuration. It was drawn out of the duct using a centrifugal blower providing a volumetric flow of $85.5 \mathrm{~m}^{3} / \mathrm{h}$. To measure the air flow accurately $( \pm 1.5 \%)$ an orifice plate setup was constructed according to BS EN ISO 5167-1:2003 [62] and attached to the blower outlet. An inclined manometer was used to measure the pressure difference across the orifice plate with a reading error of $\pm 2.5 \mathrm{~Pa}$.

The performance of the desiccator was mainly assessed under humid conditions (RH 67-75\%). Some experiments were carried out under drier conditions (RH 60$63 \%$ ) but showed a significant drop of the performance and are not reported here (see ref. [51] for more details). Table 1 shows the conditions of the five experiments of this study. The initial concentration of the $\mathrm{MgCl}_{2}$ solution was in the range 0.34$0.36 \mathrm{~kg}$ of solute / $\mathrm{kg}$ of solution, corresponding to $39 \%-32 \%$ equilibrium relative humidity, as these high concentrations would be needed to provide liquid desiccant cooling for greenhouses.

The water rate of absorption $\dot{m}_{\text {abs }}$ was calculated by the following formula

$\dot{m}_{\mathrm{abs}}=\dot{m}_{\mathrm{a}} \cdot\left(\omega_{\text {in }}-\omega_{\text {out }}\right)$

where $\omega_{\text {in }}$ and $\omega_{\text {out }}$ are the absolute humidities of the inlet and outlet air respectively.

The enthalpy effectiveness and moisture effectiveness of the dehumidifier describe the heat and mass transfer performances. They were calculated as the change in enthalpy (or absolute humidity) across the dehumidifier, as a fraction of the maximum change possible if the air were brought into equilibrium with the desiccant solution.

\section{Results}

This section presents the results from the experiments and makes comparisons with the predictions of the theoretical models for the regenerator and the desiccator.

\subsection{Regenerator}

Fig.4 shows an example of the results from one experiment for the conditions of irradiance of $760 \mathrm{~W} \mathrm{~m}$-2 and $0.0062 \mathrm{~kg} \mathrm{~s}^{-1} \mathrm{~m}^{-2}$ mass flow of desiccant per area of regenerator. Based on the entire series of similar experiments, Table 2 presents the effectiveness (averaged over the duration of the experiment) for each experiment and compares the corresponding predicted values form the model. It can be seen that the relative error was less than $7 \%$. \%. More experimental results for various irradiance and mass flow conditions similar to Fig. 4 can be found in Appendix C (see Fig. C1-5).

Fig. 5 illustrates the average effectiveness for the three experiments carried out at each value of irradiance. It also shows the corresponding range of concentrations of $\mathrm{MgCl}_{2}$ solution. The first four bars of Fig. 5 correspond to strong desiccant solution (concentrations $29-36 \%$ ) and for these the average effectiveness was $41 \%$. The last two bars of Fig. 5 show for comparison the effect of a weak desiccant solution and 
pure water on the performance of the regenerator which gave higher effectiveness values of 64 and $65 \%$ respectively.

\subsection{Desiccator}

Results from the desiccator experiments were also compared with the model predictions to verify the model accuracy. Performance of the desiccator was indicated by the mass flux (per wetted surface) of absorbed water, $\dot{m}_{\text {abs }}$ which ranged from 172-216 $\mathrm{g} \mathrm{h}^{-1} \mathrm{~m}^{-2}$ and was predicted with an error of less than 13\% (Fig.6). Average errors in the predictions air outlet temperature, the outlet liquid desiccant temperature, cooling water outlet temperature, and outlet relative humidity were $5 \%$, $9 \%, 5 \%$, and $4 \%$ respectively. The constants determined for use in the Nusselt and Sherwood correlations were as indicated in Appendix B.

Moisture effectiveness ranged from $50-65.6 \%$ while the enthalpy effectiveness varied from 54-67\%. Both moisture and enthalpy effectiveness values were predicted with an average error $8 \%$. Though the effectiveness values increased with the flow of liquid desiccant, they reached a plateau for mass flows of higher than 90 $\mathrm{kg} \mathrm{h}^{-1}$ per $\mathrm{m}^{-2}$ of desiccator face area (Fig.7).

\section{System model and predictions}

The whole system model combines the above theoretical models of the regenerator, the desiccator and the greenhouse with evaporative pad. It applies mass and energy balance to the nodes connecting these components. At each moment in time the system is assumed to be in steady state (ie. it is a pseudo-steady state model) since thermally stored energy is likely to be small compared to the flow of solar energy over time periods during which sunlight varies significantly.

The equations were coded and solved using gPROMS ${ }^{\circ}$ process modeling software. The model enables prediction of the temperature and humidity inside the greenhouse given environmental conditions (temperature, humidity and solar irradiance) and design parameters including component sizes and flow rates of the fluids in the system. For convenience, results are presented here on the basis of a greenhouse of plan area $1000 \mathrm{~m}^{2}$. Table 3 shows the values of the main parameters used in the simulations.

The climatic data required for the analysis were obtained from Meteonorm Version 4.0 software. Cooling systems are usually employed in the hot season during the hottest hours of the day which are normally between 10:00hrs and 17:00hrs. Therefore, the hottest 3 months (with temperatures exceeding $30^{\circ} \mathrm{C}$ ) were chosen for each location and then the average hourly data over each month of ambient temperature, relative humidity and irradiance were fed into the model. Climate is hotter in low latitudes and more humid in coastal areas. Therefore, we focussed on coastal locations in the tropical and subtropical regions where the climate is most likely to be hot and more humid. Another reason for choosing coastal areas was that the greenhouse would be closer to sources of seawater and seawater brines to be used in the system.

For hot climates, the conventional method of cooling greenhouses currently is by evaporative cooling (ie. pad-and-fan systems). Therefore, simulations of the proposed liquid desiccant cooling system (LDCS) in comparison to evaporative cooling (EvCool) were carried out under the climatic conditions of the following six cities: a) Sfax, b) Messina, c) Havana, d) Chittagong, e) Muscat, f) Mumbai. The results are illustrated in Fig. 8 which shows the temperature drops below ambient 
achieved inside the greenhouse, averaged over the daytime from 10:00 to 17:00 hrs. Fig. 9 shows the predicted regenerator size for each city during the hot season.

Based on these results, the usefulness of the LDCS in facilitating cultivation during the hottest 3 months of the year is shown in Fig.10 for lettuce, soya bean, tomato and cucumber respectively. These provide example of temperate, subtropical, tropical and heat-tolerant tropical crops respectively. Table 4 shows the assumed ranges temperatures for viable and optimal cultivation for each of these crops.

\section{Discussion and Conclusions}

To investigate the feasibility of a $\mathrm{MgCl}_{2}$ liquid desiccant system for greenhouse cooling, we have developed appropriate theories for the regenerator and desiccator and verified them through laboratory scale experiments. The regenerator was of open plate type; the desiccator was of cross flow configuration and consisted of CELdek® porous medium. The theories presented here are adapted from existing theories that were previously applied successfully to systems that were of similar design but used different desiccants. Specifically, our theoretical model of the regenerator is based on the work of Collier [35]; and our model for the desiccator is based on the works by Liu et al [21-23, 52] and Khan [53, 54], and on the dimensionless mass and heat transfer correlations of Chung et al [16]. Our study has shown good agreement between the experimental and predicted values of the mass flow rate of water evaporation/absorption, with errors of less than $7 \%$ and $13 \%$ for the regenerator and desiccator respectively.

The accuracies of these predictions are similar to those reported by others. Thus the $7 \%$ accuracy obtained for the regenerator is comparable to the accuracy of $9.3 \%$ reported by Kumar and Devotta [11] in a study using $\mathrm{LiCl}$ and an open regenerator. As regards the desiccator, Table 5 compares this study with two other recent studies that also used cellulose porous media though different types of desiccant to that used here. All three desiccator studies show errors in prediction of moisture and enthalpy effectiveness of about 8-10\%.

The accuracies of these models are adequate for the purpose of prediction of greenhouse growing conditions. Thus, the models have been combined with a greenhouse model in order to simulate the performance of the proposed liquid desiccant cooling system (LDCS) under different climate conditions. The simulations showed that LDCS would lower the greenhouse temperature by $5.5-7.5^{\circ} \mathrm{C}$ in places such as Mumbai, Muscat, Chittagong, Havana, Messina and Sfax, compared to evaporative cooling. They also showed that the required regenerator area can vary significantly (from $500 \mathrm{~m}^{2}$ to $4000 \mathrm{~m}^{2}$ per $1000 \mathrm{~m}^{2}$ of greenhouse plan area) depending on the location and time of year, with larger variations at more humid places (Chittagong, Mumbai and Havana). In some cases the large size of open regenerator may not be practical and future work may need to consider alternative designs e.g. using glazed covers.

We consider now the implications for each of the different crops studied. During the hottest 3 months of the year, the model predictions show that:

- For lettuce, which represents a temperate crop, the LDCS enables continuous cultivation either providing viable growing conditions (at Muscat, Havana, Chittagong and Mumbai) or optimal ones (at Messina and Sfax). In contrast, conventional evaporative cooling does not provide low enough temperatures for optimal growing conditions during the hottest 3 months at any of the locations studied. 
- For tomato and cucumber (representing tropical and heat-tolerant crops respectively) the LDCS provides temperature conditions for optimal growth at all locations, although in Sfax and Chittagong it provides more cooling than needed. In comparison, evaporative cooling is adequate to provide only viable growing temperatures (apart from in Messina where it provides optimal conditions) during the hottest 3 months.

- For soya bean, which is classed as a sub-tropical crop, LDCS provides temperatures that never exceed the optimum range, but in some locations (eg. Messina and Sfax) produces more cooling than needed. Similarly, evaporative cooling can achieve optimum temperatures at all locations studied except Muscat where it provides enough cooling for only viable growing conditions.

At times of year when LDCS provides lower temperatures than needed, it could be switched off or run in evaporative cooling mode only. With appropriate control of this kind, the system could enable year-round cultivation of all the crops and at all the locations studied. At some locations the system has capacity to cope with increased temperatures in the future. The findings of this study deserve further investigation and testing by means of a pilot greenhouse installation at an appropriate location.

\section{Acknowledgements}

GL acknowledges financial support from the Greek State Scholarship Foundation. PAD acknowledges assistance from the Royal Society in the form of a Research Grant.

\section{References}

[1] Canning P, Charles A, Huang S, Polenske KR, Waters A. Energy Use in the U.S. Food System. USDA Economic Research Service Report No. ERR-94; 2010.

[2] IPCC. Climate Change 2007: Synthesis Report. Contribution of Working Groups I, II and III to the Fourth Assessment Report of the Intergovernmental Panel on Climate Change In: Core Writing Team P, R.K and Reisinger, A., editor. Geneva, Switzerland: IPCC 2007. p. 104 pp.

[3] United Nations DESA, Population Division. World Population Prospects: The 2010 Revision, Press Release. 2011.

[4] Davies PA. A solar cooling system for greenhouse food production in hot climates. Solar Energy. 2005;79(6):661-8.

[5] Baum VA, Kakabaev A, Khandurdyev A. Efficiency of a solar cooler with an open flat solution regenerator. Geliotekhnika. 1972;8(1):34-9.

[6] Kakabaev A, Khandurdyev A, Klyshchaeva O, Kurbanov N. A large-scale solar air-conditioning pilot plant and its test results. International Chemical Engineering. 1976;16(1):60-4.

[7] Kakabaev A, Khandurdyev A. Absorption solar refigeration unit with open regeneration of solution. Geliotekhnika. 1969;5(4):28-32.

[8] Hawlader MNA, Stack AP, Wood BD. Performance Evaluation of Glazed and Unglazed Collectors/Regenerators in a Liquid Absorbent Open-Cycle Absorption Cooling System. International Journal of Sustainable Energy. 1992;11(3):135 - 64.

[9] Kabeel AE. Augmentation of the performance of solar regenerator of open absorption cooling system. Renewable Energy. 2005;30(3):327-38. 
[10] Kaudinya JV, Kaushik SC. Experimental validation of theoretical studies on open and forced flow solar regenerator. International Journal of Solar Energy. 1986;4:1323.

[11] Kumar P, Devotta S. Modelling of the thermal behaviour of a solar regenerator for open-cycle cooling systems. Applied Energy. 1989;33(4):287-95.

[12] Mullick SC, Gupta MC. Solar desorption of absorbent solutions. Solar Energy. 1974;16(1):19-24.

[13] Novak KS, Wood BD. Solar Collector/Regenerator performance based on experimental heat and mass transfer correlations. Conference Solar Collector/Regenerator performance based on experimental heat and mass transfer correlations, Montreal, Canada vol. 1. p. 669-73.

[14] Chung T-W. Predictions of moisture removal efficiencies for packed-bed dehumidification systems. Gas Separation \& Purification. 1994;8(4):265-8.

[15] Chung T-W, Ghosh TK, Hines AL. Dehumidification of Air by Aqueous Lithium Chloride in a Packed Column. Separation Science and Technology. 1993;28(1):533 50.

[16] Chung T-W, Ghosh TK, Hines AL. Comparison between Random and Structured Packings for Dehumidification of Air by Lithium Chloride Solutions in a Packed Column and Their Heat and Mass Transfer Correlations. Industrial \& Engineering Chemistry Research. 1996;35(1):192-8.

[17] Chung T-W, Wu W-Y, Yan W-J, Huang C-L. Efficiency of a Liquid Desiccant Dehumidification System Regenerated by Using Solar Collectors/ Regenerators with Photovoltaic Fans. Separation Science and Technology. 1995;30(6):1039 - 45.

[18] Factor HM, Grossman G. A packed bed dehumidifier/regenerator for solar air conditioning with liquid desiccants. Solar Energy. 1980;24(6):541-50.

[19] Gommed K, Grossman G. Experimental investigation of a liquid desiccant system for solar cooling and dehumidification. Solar Energy. 2007;81(1):131-8.

[20] Jain S, Dhar PL, Kaushik SC. Experimental studies on the dehumidifier and regenerator of a liquid desiccant cooling system. Applied Thermal Engineering. 2000;20(3):253-67.

[21] Liu X, Jiang Y, Xia J, Chang X. Analytical solutions of coupled heat and mass transfer processes in liquid desiccant air dehumidifier/regenerator. Energy Conversion and Management. 2007;48(7):2221-32.

[22] Liu XH, Qu KY, Jiang Y. Empirical correlations to predict the performance of the dehumidifier using liquid desiccant in heat and mass transfer. Renewable Energy. 2006;31(10):1627-39.

[23] Liu XH, Zhang $Y, Q u K Y$, Jiang $Y$. Experimental study on mass transfer performances of cross flow dehumidifier using liquid desiccant. Energy Conversion and Management. 2006;47(15-16):2682-92.

[24] Longo GA, Gasparella A. Experimental and theoretical analysis of heat and mass transfer in a packed column dehumidifier/regenerator with liquid desiccant. International Journal of Heat and Mass Transfer. 2005;48(25-26):5240-54.

[25] Moon CG, Bansal PK, Jain S. New mass transfer performance data of a crossflow liquid desiccant dehumidification system. International Journal of Refrigeration. 2009;32(3):524-33.

[26] Potnis SV, Lenz TG. Dimensionless Mass-Transfer Correlations for Packed-Bed Liquid-Desiccant Contactors. Ind Eng Chem Res. 1996;35(11):4185-93.

[27] Saman WY, Alizadeh S. An experimental study of a cross-flow type plate heat exchanger for dehumidification/cooling. Solar Energy. 2002;73(1):59-71.

[28] Yin Y, Zhang X. A new method for determining coupled heat and mass transfer coefficients between air and liquid desiccant. International Journal of Heat and Mass Transfer. 2008; In Press, Corrected Proof.

[29] Dai YJ, Wang RZ, Zhang HF, Yu JD. Use of liquid desiccant cooling to improve the performance of vapor compression air conditioning. Applied Thermal Engineering. 2001;21(12):1185-202. 
[30] Gommed K, Grossman G. A Liquid Desiccant System for Solar Cooling and Dehumidification. Journal of Solar Energy Engineering. 2004;126(3):879-85.

[31] Mei L, Dai YJ. A technical review on use of liquid-desiccant dehumidification for air-conditioning application. Renewable and Sustainable Energy Reviews. 2008;12(3):662-89.

[32] Oliveira AC, Afonso CF, Riffat SB, Doherty PS. Thermal performance of a novel air conditioning system using a liquid desiccant. Applied Thermal Engineering. 2000;20(13):1213-23.

[33] Davies PA, Knowles PR. Seawater bitterns as a source of liquid desiccant for use in solar-cooled greenhouses. Desalination. 2006;196(1-3):266-79.

[34] Lychnos G, Fletcher JP, Davies PA. Properties of seawater bitterns with regard to liquid-desiccant cooling. Desalination. 2010;250(1):172-8.

[35] Collier RK. The analysis and simulation of an open cycle absorption refrigeration system. Solar Energy. 1979;23(4):357-66.

[36] Gandhidasan P, Sriramulu V, Gupta MC. Heat and mass transfer in a solar regenerator. The Chemical Engineering Journal. 1981;21(1):59-63.

[37] Gandhidasan P. Simple analysis of a forced flow solar regeneration system. Journal of Energy 1982;6(6):436-7

[38] Peng CP, Howell JR. Analysis of open inclined surface solar regenerators for absorption cooling applications--Comparison between numerical and analytical models. Solar Energy. 1982;28(3):265-8.

[39] Gandhidasan P. A simple analysis of an open regeneration system. Solar Energy. 1983;31(3):343-5.

[40] Gandhidasan P. Thermal Performance Predictions and Sensitivity Analysis for a Parallel Flow Solar Regenerator. Journal of Solar Energy Engineering. 1983;105(2):224-8.

[41] Gandhidasan P. Theoretical study of tilted solar still as a regenerator for liquid desiccants. Energy Conversion and Management. 1983;23(2):97-101.

[42] GANDHIDASAN P. Comparative study of two types of solar regenerators for liquid absorption dehumidification system. ASHRAE transactions. 1984;90(2):78-84

[43] Peng CSP, Howell JR. The Performance of Various Types of Regenerators for Liquid Desiccants. Journal of Solar Energy Engineering. 1984;106(2):133-41.

[44] Novak KS, Wood BD, Nelson DJ. Experimentally determined correlations for solar collector/regenerator heat and mass transfer. ASME. 1985;No 85-WA/SOL-7.

[45] Nelson DJ, Wood BD. Evaporation Rate Model for a Natural Convection Glazed Collector/Regenerator. Journal of Solar Energy Engineering. 1990;112(1):51-7.

[46] Haim I, Grossman G, Shavit A. Simulation and analysis of open cycle absorption systems for solar cooling. Solar Energy. 1992;49(6):515-34.

[47] Kaushik SC, Kaudinya JV, Yadav YK. Studies on some solar collector/regenerator systems for open cycle absorption air conditioning/liquid desiccant cooling systems. Heat Recovery Systems and CHP. 1992;12(4):357-63.

[48] Fagbenle RL, Karayiannis TG. A thermodynamic analysis of a simple open-flow solar regenerator. Applied Thermal Engineering. 1998;18(12):1359-74.

[49] Alizadeh S, Saman WY. Modeling and performance of a forced flow solar collector/regenerator using liquid desiccant. Solar Energy. 2002;72(2):143-54.

[50] Wood BD, Buck GA, Siebe DA, Breslauer M. Performance characteristics of an open-flow liquid desiccant solar collector/regenerator in a hot arid climate. ISES Solar World Congress. 1983:337-42.

[51] Lychnos G. Feasibility of a Solar-Powered Liquid Desiccant Cooling System for Greenhouses, PhD thesis [PhD]. Birmingham: Aston University, 2010.

[52] Liu XH, Jiang $Y, Q u K Y$. Heat and mass transfer model of cross flow liquid desiccant air dehumidifier/regenerator. Energy Conversion and Management. 2007;48(2):546-54.

[53] Khan AY. Cooling and dehumidification performance analysis of internally-cooled liquid desiccant absorbers. Applied Thermal Engineering. 1998;18(5):265-81. 
[54] Khan AY, Ball HD. Development of a generalized model for performance evaluation of packed-type liquid sorbent dehumidifiers and regenerators. ASHRAE transactions. 1992;98(1):525-33.

[55] Kittas C, Bartzanas T, Jaffrin A. Temperature Gradients in a Partially Shaded Large Greenhouse equipped with Evaporative Cooling Pads. Biosystems Engineering. 2003;85(1):87-94.

[56] Cengel YA. Heat and mass transfer: a practical approach. 3 ed. Singapore: McGraw-Hill Education, 2006.

[57] Incropera FP, Dewitt DP, Bergman TL, Lavine AS. Fundamentals of heat and mass transfer. 6th ed. USA: John Wiley \& Sons, Inc, 2007.

[58] Lobo VMM. Handbook of electrolyte solutions. Parts A \& B: Elsevier, 1989.

[59] Zaytsev ID, Aseyev GG. Properties of aqueous solutions of electrolytes. Boca Raton, London: CRC, 1992.

[60] National Engineering Laboratory B, R. W. Steam tables 1964 : physical properties of water and steam, 0-800 degrees C / 0-1000 bars. Prep. by R.W.Bain. Edinb. :: H.M.S.O, 1964.

[61] Perry RH, Green DW, Maloney JO. Perry's Chemical engineers' handbook. 6th ed. New York: McGraw-Hill, 1984.

[62] BSENISO5167-1:2003. Measurement of fluid flow by means of pressure differential devices inserted in circular cross-section conduits running full. General principles and requirements

[63] Kumar DS. Heat And Mass Transfer. 5 ed: S. K. Kataria \& Sons, 2003

[64] Treybal RE. Mass transfer operations. 3 ed. USA: McGraw-Hill, 1980.

[65] Kocamustafaogullari G, Chen IY. Falling film heat transfer analysis on a bank of horizontal tube evaporator. AIChE. 1988;34(9):1539-49.

[66] Sanitjai S, Goldstein RJ. Forced convection heat transfer from a circular cylinder in crossflow to air and liquids. International Journal of Heat and Mass Transfer. 2004;47(22):4795-805. 


\section{Appendices}

Note to Editor: these Appendices are intended as supplementary on-line material

Appendices $A$ and $B$ show the details of the equations used in the theoretical models. Appendix $C$ shows supplementary experimental results from the regenerator.

\section{Appendix A. Regenerator}

The mass flow rate of evaporation per unit width of the regenerator surface is given by:

$$
\begin{aligned}
\dot{m}_{\mathrm{ev}}=\frac{\dot{m}_{\mathrm{s}, \mathrm{in}} \cdot\left[\frac{\Gamma}{\mathrm{B}} \cdot K_{2}+h_{\mathrm{m}} \cdot\left(P_{0}-P_{a m b}\right)\right]}{K_{1}-K_{2}} e^{\frac{K_{\mathrm{s}} \cdot x}{\dot{m}_{\mathrm{sin}}}} & -\frac{\dot{m}_{\mathrm{s}, \mathrm{in}} \cdot\left[\frac{\Gamma}{\mathrm{B}} \cdot K_{1}+h_{\mathrm{m}} \cdot\left(P_{0}-P_{a m b}\right)\right]}{K_{1}-K_{2}} e^{\frac{K_{2} \cdot x}{\dot{m}_{\mathrm{s}, \mathrm{in}}}}+\frac{\Gamma}{\mathrm{B}} \cdot \dot{m}_{\mathrm{s}, \mathrm{in}}
\end{aligned}
$$

where:

$$
K_{1}=\frac{-\mathrm{A}+\sqrt{\mathrm{A}^{2}-4 \mathrm{~B}}}{2}, K_{1}=\frac{-\mathrm{A}-\sqrt{\mathrm{A}^{2}-4 \mathrm{~B}}}{2}
$$

and

$$
\begin{aligned}
& \mathrm{A}=\frac{U_{\mathrm{L}}}{C_{\mathrm{ps}}}+\frac{h_{\mathrm{m}} \cdot b}{X_{\mathrm{s}, \text { in }}}+\frac{h_{f g} \cdot a \cdot k_{\mathrm{p}}}{C_{\mathrm{ps}}} \\
& \mathrm{B}=\frac{U_{\mathrm{L}} \cdot b \cdot h_{\mathrm{m}}}{X_{\mathrm{s}, \text { in }} \cdot C_{\mathrm{p}}} \\
& \Gamma=\frac{h_{\mathrm{m}}}{C_{\mathrm{ps}}} \cdot\left[a \cdot\left(I_{\mathrm{R}}+U_{\mathrm{L}} \cdot T_{\mathrm{amb}}\right)+U_{\mathrm{L}} \cdot\left(\frac{b}{X_{\mathrm{s}, \mathrm{in}}}-P_{\mathrm{amb}}+c\right)\right] \\
& X_{\mathrm{s}}^{\mathrm{o}}=\frac{\dot{m}_{\mathrm{des}}}{\dot{m}_{\mathrm{s}, \text { in }}}
\end{aligned}
$$

where $\dot{m}_{\mathrm{s}, \mathrm{in}}$ is the liquid desiccant mass flow rate per unit width, $\dot{m}_{\mathrm{des}}$ is the salt mass flow rate per unit width, $h_{m}$ is the mass transfer coefficient based on pressure gradient, $P_{0}$ and $P_{\mathrm{amb}}$ are the initial vapour pressure of the solution and the ambient pressure respectively, $U_{\mathrm{L}}$ is the overall heat loss coefficient, $X_{\mathrm{s}, \mathrm{in}}$ is the initial liquid desiccant concentration and $C_{\mathrm{ps}}$ is the specific heat capacity of the liquid desiccant.

The following linear expression is used to approximate the variation of vapour pressure with temperature and concentration over small intervals:

$$
P_{\mathrm{s}}=a \cdot T_{\mathrm{s}}+\frac{b}{X_{\mathrm{s}}}+c
$$


$a, b$ and $c$ are calculated from experimental values [59] - see Table A.1. The detailed derivation of the above analytical solution can be found in ref. [51].

Table A.1 The empirical values used in equation A.2 for $\mathrm{MgCl}_{2}$ aqueous solutions

\begin{tabular}{|c|c|c|c|c|l|}
\hline $\begin{array}{l}\text { Temperature } \\
\text { range }\left({ }^{\circ} \mathrm{C}\right)\end{array}$ & $\begin{array}{l}\text { Concentration } \\
\text { range }(\mathrm{kg} / \mathrm{kg} \%)\end{array}$ & $\begin{array}{l}\text { Average } \\
\text { percent error }\end{array}$ & $a$ & $b$ & $c$ \\
\hline $20-25$ & $28-34$ & 2 & 76 & 793 & -23710 \\
\hline $25-30$ & $28-36$ & 4 & 99 & 1084 & -31600 \\
\hline $30-35$ & $28-36$ & 4 & 135 & 1493 & -43760 \\
\hline $35-40$ & $28-36$ & 5 & 136 & 1494 & -43920 \\
\hline
\end{tabular}

$U_{\mathrm{L}}$ is expressed as the sum of the radiant heat transfer coefficient and the convective heat transfer coefficient at the regenerator surface:

$$
U_{\mathrm{L}}=h_{\mathrm{rad}}+h_{\text {conv }}
$$

Based on the Stefan-Boltzmann law the radiation heat transfer coefficient can be expressed:

$$
h_{\mathrm{rad}}=\frac{\sigma \cdot \varepsilon \cdot\left(T^{4}-T_{\mathrm{sky}}^{4}\right)}{\left(T-T_{\mathrm{amb}}\right)}
$$

where $\sigma$ is the Stefan-Boltzmann constant, $\varepsilon$ is the emissivity, $T_{\text {sky }}$ is the effective sky radiation (in this analysis we used $T_{\text {amb }}$ instead because all the experiments were conducted indoors).

$$
h_{\text {conv }}=\frac{\overline{N u} \cdot k}{L_{c}}
$$

where $\overline{N u}$ is the average Nusselt number, $k$ is the themal conductivity of air and $L_{\mathrm{c}}$ the characteristic length.

Regarding $h_{m}$ the following equations were applied:

$$
h_{\mathrm{m}}=\frac{h_{\mathrm{D}}}{R \cdot T}
$$

see ref [63]; where $R$ is the air gas constant and $h_{\mathrm{D}}$ is the mass transfer coefficient based on concentration gradient.

$$
h_{\mathrm{D}}=\frac{\overline{S h} \cdot D_{\mathrm{w}-\mathrm{a}}}{L_{\mathrm{c}}}
$$


see ref [57]; where $\overline{S h}$ is the average Sherwood number, $D_{\text {w-a }}$ is the binary diffusion coefficient of water vapour in air and $L_{\mathrm{c}}$ is the characteristic length

Thus by knowing correlations of the average Nusselt number $\overline{N u}$ and the average Sherwood number $\overline{S h}$ we can predict $h_{\text {conv }}$ and $h_{\mathrm{m}}$. According to the literature simple empirical correlations for $\overline{N u}$ and $\overline{S h}$ in natural convection are of the form:

$$
\left.\begin{array}{l}
\overline{N u}=C \cdot(G r \cdot P r)^{n} \\
\overline{S h}=C \cdot(G r \cdot S c)^{n}
\end{array}\right\}
$$

where $\mathrm{Gr}, \mathrm{Pr}$ and $S c$ are the Grashoff, Prandtl and Schmidt numbers respectively.C and $n$ are constants that depend on the geometry and orientation of the surface, the flow regime and thermo-physical properties of the fluid [56].

Published empirical correlations of heat and mass transfer are available for geometries such as a flat plate [57]. Correlations for a flat plate were used by Collier [35] for a regenerator model. However his study was theoretical without comparison to experimental data. In practice, differences are likely to arise due to factors such as:

a) surface roughness

b) non-uniform surface wetting

c) solution flow patterns

d) laboratory environment not fully controlled (varying ambient $\mathrm{RH}$ and temperature)

In this work there was a significant departure from the published correlations so new ones were used based on experiment. To derive these, an energy balance was considered:

$Q_{\text {solar }}+H_{\text {in }}=H_{\text {out }}+Q_{\text {loss }}+H_{\text {ev }}$

All the variables were determined experimentally except $Q_{\text {loss }}$.

$Q_{\text {solar }}=I_{\mathrm{R}} \cdot \alpha \cdot A-I_{\text {ref }} \cdot A$

$H_{\mathrm{in}}=\dot{m}_{\mathrm{s}, \mathrm{in}} \cdot C_{\mathrm{p}, \mathrm{s}} \cdot T_{\mathrm{in}}$

$H_{\text {out }}=\dot{M}_{\mathrm{s}, \mathrm{in}} \cdot C_{\mathrm{p}, \mathrm{s}} \cdot T_{\text {out }}$

$H_{\mathrm{ev}}=M_{\mathrm{ev}} \cdot h_{\mathrm{fg}}$

where $I_{\text {ref }}$ is the reflected light at the liquid surface. The angle of incidence was taken to be $15^{\circ}$ and then the well established Fresnel equations were used to calculate the reflectance which was assumed specular. It was found that only $3.3 \%$ of the irradiance was reflected.

By substituting (A.9), (A.10), (A.11), (A.12) in (A.8) $Q_{\text {loss }}$ was calculated:

$Q_{\text {loss }}=U_{\mathrm{L}} \cdot\left(T_{\mathrm{s}}-T_{\text {amb }}\right)$

Hence for each experiment a total heat loss coefficient $U_{\mathrm{L}}$ was calculated and then the average Nusselt number was calculated from equations (A.3), (A.4) and (A.5). 
The Rayleigh number was in the range of $10^{4}-10^{7}$; hence the flow of air was in the laminar region in all the experiments carried out.

Based on the general empirical correlation for natural convection over a horizontal flat plate and using solver function in Excel (setting the percent error of the predicted average Nusselt number to be 0 ) the following Nusselt number correlation was derived

$$
\overline{N u}=0.54 \cdot \operatorname{Pr}^{0.25} \cdot G r_{\text {tot }}^{0.421}
$$

The mass rate of evaporation can be expressed:

$$
h_{\mathrm{D}}=\frac{\dot{m}_{e v}}{\rho_{a} \cdot\left(\omega_{\mathrm{int}}-\omega_{a m b}\right) \cdot A}
$$

where $\rho_{a}$ is the density of the air, $\omega_{\text {int }}$ and $\omega_{\text {amb }}$ are the moisture content at the interface of the solution-air and the moisture content of the ambient air respectively; $A$ is the total area of the regenerator.

Substituting (A. 15) in (A. 7) and solving for $\overline{S h}$ yields:

$$
\overline{S h}=\frac{\dot{m}_{e v} \cdot L_{\mathrm{c}}}{\rho_{a} \cdot D_{\mathrm{w}-\mathrm{a}} \cdot\left(\omega_{\mathrm{int}}-\omega_{a m b}\right) \cdot A}
$$

which gives the experimental Sherwood number. Since there is an analogy between heat and mass transfer, the Sherwood number correlation was derived following the same method as with Nusselt number above

$$
\overline{S h}=0.54 \cdot S c^{0.25} \cdot G r_{\text {tot }}^{0.427}
$$

All the physical properties of air and water used in this model were calculated based on well known formulae published in literature or were calculated using polynomial regression based on experimental data $[56,57]$.

Once the mass rate of evaporation $\dot{m}_{\mathrm{ev}}$ has been calculated, it is used to predict the effectiveness of the regenerator which compares the evaporation rate with that achievable if all the incident solar energy were converted into latent heat of evaporation.

$$
\eta=\frac{\dot{m}_{\mathrm{ev}} h_{\mathrm{fg}}}{I_{R} A}
$$

The effectiveness is a key non-dimensional parameter in describing the performance of the regenerator.

The model presented here predicts the mass flux of water evaporation occurring at the regenerator assuming that the whole surface area of the regenerator is wetted. To account for ineffectiveness due to bad wetting, salt deposition and solution flow patterns, the model deviations were calculated and then the average one for given 
irradiance and solution mass flow (see table A.2) was used as a constant to correct the predicted values.

Table A.2 Average model deviation for the mass flux of evaporated water.

\begin{tabular}{|c|c|c|c|c|}
\hline \multicolumn{5}{|c|}{ Constants } \\
\hline$\dot{m}_{\mathrm{s}, \text { in }}$ & 400 & 600 & 970 & 760 \\
\hline 0.0021 & 0.94 & 0.80 & 0.78 & 0.84 \\
\hline 0.0041 & 0.62 & 0.71 & 0.68 & 0.71 \\
\hline 0.0065 & 0.63 & 0.64 & 0.63 & 0.62 \\
\hline
\end{tabular}

\section{Appendix B. Desiccator}

The partial vapour pressure water vapour in the ambient air is higher than the partial vapour pressure of the liquid desiccant at its surface; this drives mass transfer. If we define as the wetted area of packing per volume $\left(\mathrm{m}^{2} \mathrm{~m}^{-3}\right)$ to be

$$
\alpha_{\mathrm{w}}=\frac{\alpha}{V}
$$

where $\alpha$ is the wetted surface area and $V$ is the volume. Then if we take a control volume (see Fig.2) the mass transfer equation can be defined in an algebraic form as $\dot{m}_{\mathrm{a}} \cdot \Delta \omega_{\mathrm{a}, 1-2}=h_{\mathrm{D}} \cdot\left(\omega_{\mathrm{Ts}, \mathrm{sat}}-\omega_{\mathrm{a}}\right) \cdot \alpha_{\mathrm{w}} \cdot \delta x \cdot \delta z \cdot \delta y$

where $h_{\mathrm{D}}$ is the mass transfer coefficient, $\omega_{\mathrm{Ts}, \text { sat }}$ is the absolute humidity of the air in equilibrium with the desiccant solution, $\omega_{\mathrm{a}}$ is the absolute humidity of the air; $\delta x, \delta z$ and $\delta y$ are the height, length and width of the control volume respectively.

Heat transfer takes place between the air and the liquid desiccant surface. This can be expressed:

$\dot{m}_{\mathrm{a}} \cdot \Delta T_{\mathrm{a}, 1-2}=h_{\mathrm{c}} \cdot\left(T_{\mathrm{s}}-T_{\mathrm{a}}\right) \cdot \alpha_{\mathrm{w}} \cdot \delta x \cdot \delta z \cdot \delta y$

where $h_{\mathrm{c}}$ is the heat transfer coefficient.

The enthalpy change of air can be defined from the enthalpy equation of moist air as

$$
\Delta h_{\mathrm{a}, 1-2}=C p_{\mathrm{a}} \cdot \Delta T_{\mathrm{a}, 1-2}+h_{f g} \cdot \Delta \omega_{\mathrm{a}, 1-2}
$$

If we define the Lewis number as

$$
L e=\frac{h_{\mathrm{C}}}{h_{\mathrm{D}} \cdot C p_{\mathrm{a}} \cdot \rho_{\mathrm{a}}}
$$

and the Number of Transfer Units (NTU) based on mass to be

$$
N T U=\frac{h_{D} \cdot L \cdot W \cdot H \cdot \alpha_{\mathrm{w}} \cdot \rho_{\mathrm{a}}}{\dot{M}_{\mathrm{a}}}
$$

where $L=0.3 \mathrm{~m}, W=0.1 \mathrm{~m}, H=0.1 \mathrm{~m}$ for our experimental set up, then if we combine equations (2), (3), (4), (5) and (6) we arrive at the following equation

$$
\Delta h_{\mathrm{a}, 1-2}=N T U \cdot L e \cdot\left[\left(h_{\mathrm{Ts}, \mathrm{sat}}-h_{\mathrm{a}}\right)+h_{f g} \cdot\left(\frac{1}{L e}-1\right) \cdot\left(\omega_{\mathrm{Ts}, \mathrm{sat}}-\omega_{\mathrm{a}}\right)\right] \cdot \frac{\delta y}{W}
$$


where $h_{\text {Ts.sat }}$ is the specific enthalpy of air in equilibrium with the liquid desiccant and $\omega_{\mathrm{T} s, \mathrm{sat}}$ is the saturated water content of the air at the surface of the liquid desiccant.

The air temperature change $\Delta T_{a, 1-2}$ can now be found by substituting Eq. (B.7) in Eq. (B.4) and solving for $\Delta T_{\mathrm{a}, 1-2}$.

The law of conservation of energy states (since there is no work generation, the potential and kinetic energy changes are zero and assuming there is no heat loss) that the total enthalpy change of air should be equal to the total enthalpy change of the desiccant solution and can be expressed as $\dot{m}_{\mathrm{a}} \cdot \Delta h_{\mathrm{a}, 1-2}=\dot{m}_{\mathrm{s}} \cdot \Delta h_{\mathrm{s}, 1-2}+h_{\mathrm{s}} \cdot \Delta \dot{m}_{\mathrm{s}, 1-2}$

The law of conservation of mass between the air and the solution for the control volume is

$-\dot{m}_{\mathrm{a}} \cdot \Delta \omega_{\mathrm{a}, 1-2}=\Delta \dot{m}_{\mathrm{s}, 1-2}$

the enthalpy change of the desiccant solution is given by

$\Delta h_{\mathrm{s},-2}=C p_{\mathrm{s}} \cdot \Delta T_{\mathrm{s}, 1-2}$

If we combine Eq. (B.7), (B.8), (B.9) and (B.10) and if $h_{\mathrm{s}}=C p_{\mathrm{s}} \cdot T_{\mathrm{s}}$ ( $T_{\mathrm{s}}$ is reference temperature) then

$\Delta T_{\mathrm{s}, 1-2}=\frac{\dot{m}_{\mathrm{a}} \cdot\left\{N T U \cdot L e \cdot\left[\left(h_{\mathrm{Ts}, \mathrm{sat}}-h_{\mathrm{a}}\right)+h_{f g} \cdot\left(\frac{1}{L e}-1\right) \cdot\left(\omega_{\mathrm{T}, \mathrm{sat}}-\omega_{\mathrm{a}}\right)\right] \cdot \frac{\delta y}{W}\right\}-C p_{\mathrm{s}} \cdot T_{\mathrm{s}} \cdot \dot{m}_{\mathrm{a}} \cdot \Delta \omega_{\mathrm{a}, 1-2}}{C p_{\mathrm{s}} \cdot \dot{m}_{\mathrm{s}}}$

The law of conservation of mass for the solution states

$d\left(\dot{m}_{\mathrm{s}} \cdot X_{\mathrm{s}}\right)=0 \Rightarrow d \dot{m}_{\mathrm{s}} \cdot X_{\mathrm{s}}+d X_{\mathrm{s}} \cdot \dot{m}_{\mathrm{s}}=0$

which by integration becomes

$\Delta X_{\mathrm{s}, 1-2}=X_{\mathrm{s}, 1} \cdot\left(e^{\dot{m}_{\dot{m}_{\mathrm{s}}}^{\dot{m}_{\mathrm{s}}} \omega_{\mathrm{a}, 1-2}}-1\right)$

where $X_{\mathrm{s}}$ is the concentration of the liquid desiccant ( $\mathrm{kg}$ of solute per $\mathrm{kg}$ of solution). Note that equations (B.7) and (B.11) are equivalent to those presented by Liu et al. [21]. This physical model describes the process of heat and mass transfer that takes place in the packing material of a cross flow desiccator. The experimental cross flow desiccator constructed in the lab utilises (CELdek® 7090-15). Therefore, suitable predictive correlations of Nusselt and Sherwood numbers are needed for calculation of the heat and mass transfer coefficients $h_{\mathrm{c}}$ and $h_{\mathrm{D}}$ respectively. The Nusselt and Sherwood correlations found in the literature were developed based on the special geometrical characteristics of CELdek $\circledast$ in a similar dehumidifying process where LiCl solution was used as the liquid desiccant [16]. We verified their validity for our system based on our experimental results. Thus, in this work the Nusselt formula was used as originally presented in reference [16] and the Sherwood formula was slightly modified.

$$
\begin{aligned}
& N u=2.78 \cdot 10^{-6} \cdot \operatorname{Pr}^{1 / 3} \cdot \operatorname{Re}^{1.6} \cdot\left(1-X_{\mathrm{s}}\right)^{1.8} \cdot\left(\frac{\dot{m}_{\mathrm{s}}}{\dot{m}_{\mathrm{a}}}\right)^{0.4} \\
& S h=2.25 \cdot 10^{-5} \cdot \mathrm{Sc}^{1 / 3} \cdot \operatorname{Re} \cdot\left(1-X_{\mathrm{s}}\right)^{-0.75} \cdot\left(\frac{\dot{m}_{\mathrm{s}}}{\dot{m}_{\mathrm{a}}}\right)^{0.1}
\end{aligned}
$$


Thus the mass and heat transfer coefficients can be calculated by the following formulas:

$h_{\mathrm{D}}=\frac{S h \cdot D_{\mathrm{w}-\mathrm{a}}}{L_{\mathrm{c}}}$

where $D_{\text {w-a }}$ is the binary diffusion coefficient of water vapour in air and $L_{\mathrm{c}}$ is the characteristic length

$h_{\mathrm{c}}=\frac{N u \cdot k_{a}}{L_{c}}$

where $k_{\mathrm{a}}$ is the thermal conductivity of air.

\section{Finite volume model for cooling tubes}

The mass transfer coefficient is now expressed (in $\mathrm{kg} \mathrm{m}^{-2} \mathrm{~s}^{-1}$ ) as

$$
h_{\mathrm{D}}=\left(\frac{6 \cdot D_{\mathrm{w}-\mathrm{a}} \cdot \dot{m}_{\mathrm{s}}^{\prime}}{\pi \cdot \rho_{\mathrm{s}} \cdot \delta \cdot l}\right)^{1 / 2} \cdot \rho_{\mathrm{a}}
$$

where $D_{\mathrm{w}-\mathrm{a}}$ is the mass diffusivity of water vapour in air, $\dot{m}_{\mathrm{s}}^{\prime}$ is the liquid desiccant mass flow rate per unit width, $\rho_{\mathrm{s}}$ is the solution's density, $l$ is the length of the tube surface and $\delta$ is the solution film thickness given by (see reference [64])

$\delta=\left(\frac{3 \cdot \mu_{\mathrm{s}} \cdot \dot{m}_{\mathrm{s}}^{\prime}}{\rho_{\mathrm{s}}^{2} \cdot g}\right)^{1 / 3}$

where $\mu_{\mathrm{s}}$ is the dynamic viscosity of the solution and $g$ is the gravitational acceleration.

The energy balance equation of the control volume is now:

$$
\dot{m}_{\mathrm{a}} \cdot \Delta h_{\mathrm{a}, 1-2}+\dot{m}_{\mathrm{s}} \cdot \Delta h_{\mathrm{s}, 1-2}+\Delta \dot{m}_{\mathrm{s}, 1-2} \cdot h_{\mathrm{s}}+\dot{m}_{\mathrm{w}} \cdot \Delta h_{\mathrm{w}, 1-2}=0
$$

If we substitute equations (B.4), (B.9), (B.10) and consider that $\Delta h_{\mathrm{w}, 1-2}=C p_{\mathrm{w}} \cdot \Delta T_{\mathrm{w}, 1-2}$ in equation (20) and solve for $\Delta T_{\mathrm{a}, 1-2}$ then it yields

$$
\Delta T_{\mathrm{a}, 1-2}=\frac{\dot{m}_{\mathrm{a}} \cdot C p_{\mathrm{s}} \cdot T_{\mathrm{s}} \cdot \Delta \omega_{\mathrm{a}, 1-2}-\dot{m}_{\mathrm{s}} \cdot C p_{\mathrm{s}} \cdot \Delta T_{\mathrm{s}, 1-2}-\dot{m}_{\mathrm{a}} \cdot h_{f g} \cdot \Delta \omega_{\mathrm{a}, 1-2}-\dot{m}_{\mathrm{w}} \cdot C p_{\mathrm{w}} \cdot \Delta T_{\mathrm{w}, 1-2}}{\dot{m}_{\mathrm{a}} \cdot C p_{\mathrm{a}}}
$$

$\Delta T_{\mathrm{s}, 1-2}$ and $\Delta T_{\mathrm{w}, 1-2}$ are calculated by an effectiveness-NTU model as described below.

In the experimental setup, embedded cooling tubes were connected vertically in groups of ten. With each group considered as a cross flow heat exchanger and assuming that each tube is constantly and totally wetted by the solution, then heat exchange takes place directly and only between the solution and the surface of each cooling tube. The water is assumed to be perfectly mixed in each cross sectional area of each element. Following the well-known effectiveness-NTU method [57] the effectiveness of a cross flow heat exchanger (single pass) with $C_{\min }$ (mixed) and $C_{\max }$ (unmixed) is given by

$\varepsilon=1-\exp \left[-\frac{1}{C r} \cdot(1-\exp (-C r \cdot N T U)]\right.$

where $\mathrm{Cr}$ is the heat capacity ratio 
NTU is determined from the expression

$$
\begin{aligned}
& N T U=\frac{U_{0} \cdot A}{C_{\text {min }}} \\
& C_{\text {min }}=C_{h}=\dot{m}_{s} \cdot C p_{s}
\end{aligned}
$$

$U_{0}$ is the overall heat transfer coefficient $\left(\mathrm{W} \mathrm{m}^{-2} \mathrm{~K}^{-1}\right)$ computed for local properties and heat transfer coefficients, given from the following formula $[56,57]$ :

$$
U_{0}=\left[\left(\frac{1}{h_{\theta}}\right)+\left(\frac{1}{h_{w}}\right)+\left(\frac{\ln \left(\frac{r_{2}}{r_{1}}\right)}{2 \cdot \pi \cdot \delta l \cdot k_{c o p}}\right)+4 \cdot R f\right]^{-1}
$$

where $\delta l$ is the length of the tube, $r_{2}$ its external diameter and $r_{1}$ the internal diameter, $k_{\text {cop }}$ is the thermal conductivity of copper, $h_{\theta}$ is the heat transfer coefficient for external flow of solution at the tube surface based on [65]:

$h_{\theta}=\frac{0.687 \cdot \mathrm{Re}_{s}^{0.11} \cdot N u_{\theta} \cdot k_{\text {sol }}}{L_{c, \text { tube }}}$

with the Reynolds number given by

$$
\operatorname{Re}_{s}=\frac{4 \cdot \dot{m}_{\mathrm{s}, \text { tube }}}{\pi \cdot \frac{D}{2} \cdot \mu_{\mathrm{s}}}
$$

(see reference [20]). $N u_{\theta}$ is the Nusselt number for external flow determined from the expression

$N u_{\theta}=\left(0.35+0.34 \cdot \operatorname{Re}_{s}^{0.5}+0.15 \cdot \operatorname{Re}_{s}^{0.58}\right) \cdot \operatorname{Pr}_{\mathrm{s}}^{0.3}$

as in [66].

$h_{\mathrm{w}}$ is the heat transfer coefficient of the internal flow of water defined as

$h_{\mathrm{w}}=\frac{N u_{\mathrm{D}} \cdot k_{\mathrm{w}}}{D}$

$N u_{\mathrm{D}}$ is the Nusselt number, which for fully developed internal laminar flow ( $\operatorname{Re}_{w} \prec 2300$ ) in tubes with uniform heat flux is considered constant

$N u_{\mathrm{D}}=4.36$

$\mathrm{Pr}_{\mathrm{s}}$ is the solution Prandtl number defined by

$\operatorname{Pr}_{\mathrm{s}}=\frac{C p_{\mathrm{s}} \cdot \mu_{\mathrm{s}}}{k_{\mathrm{s}}}$

The temperature of the solution at the outlet is

$T_{\mathrm{s}}{ }^{\text {out }}=T_{\mathrm{s}}^{\text {in }}-\varepsilon \cdot\left(T_{\mathrm{s}}^{\text {in }}-T_{\mathrm{w}}{ }^{\text {in }}\right)$

The temperature of water at the outlet is

$$
T_{\mathrm{w}}{ }^{\text {out }}=T_{\mathrm{w}}{ }^{\text {in }}+\left[\frac{\varepsilon \cdot \dot{m}_{\mathrm{s}, \text { tube }} \cdot C p_{\mathrm{s}} \cdot\left(T_{\mathrm{s}}^{\text {in }}-T_{\mathrm{w}}{ }^{\text {in }}\right)}{\dot{m}_{\mathrm{w}, \text { tube }} \cdot C p_{\mathrm{w}}}\right]
$$




\section{Appendix C. Experimental measurements from the regenerator}

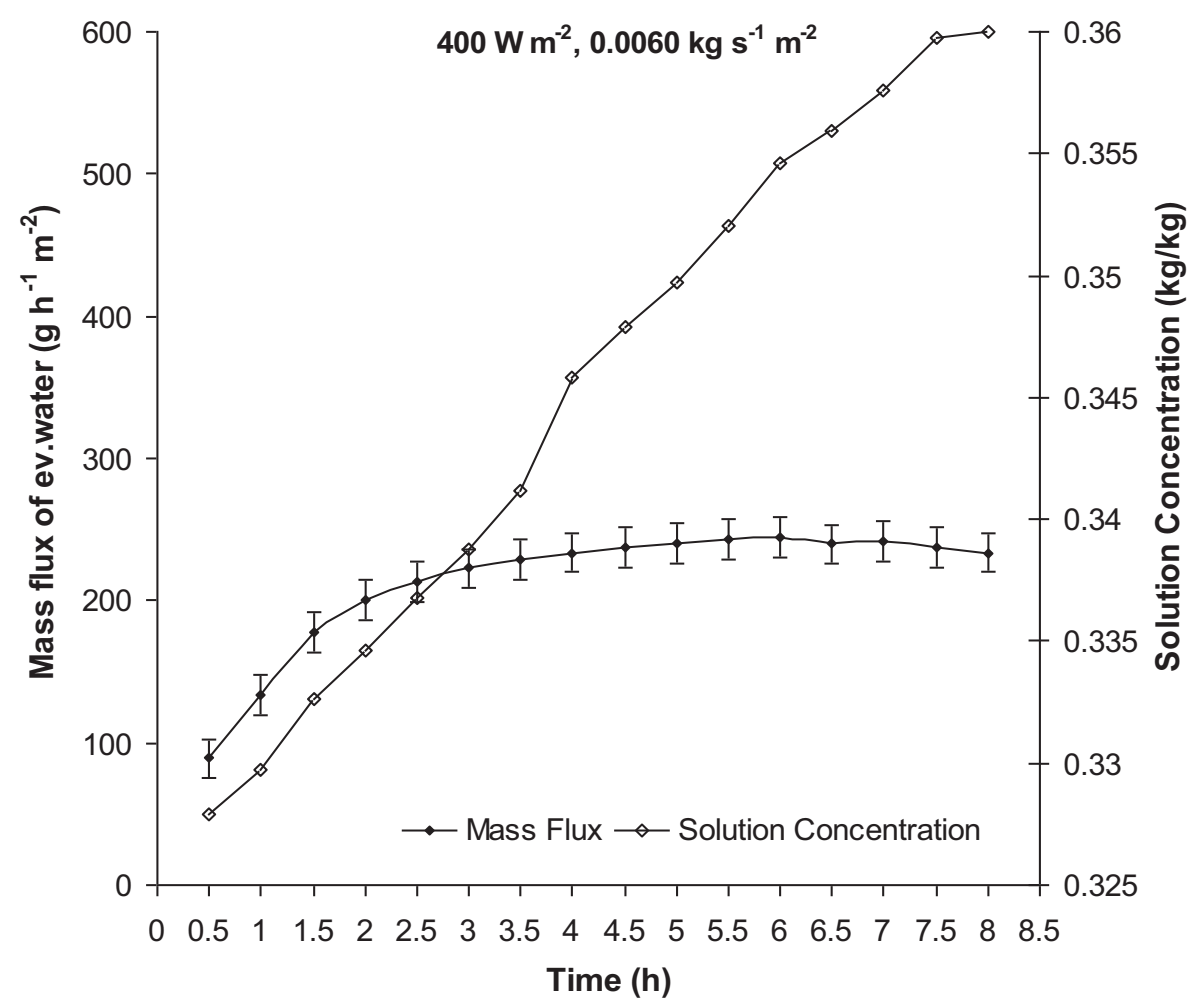

Fig. C1: Mass flux of evaporated water and liquid desiccant concentration at $400 \mathrm{~W}$ $\mathrm{m}^{-2}$ irradiance and $0.0062 \mathrm{~kg} \mathrm{~s}^{-1}$ flow of liquid desiccant per $\mathrm{m}^{2}$ of regenerator.

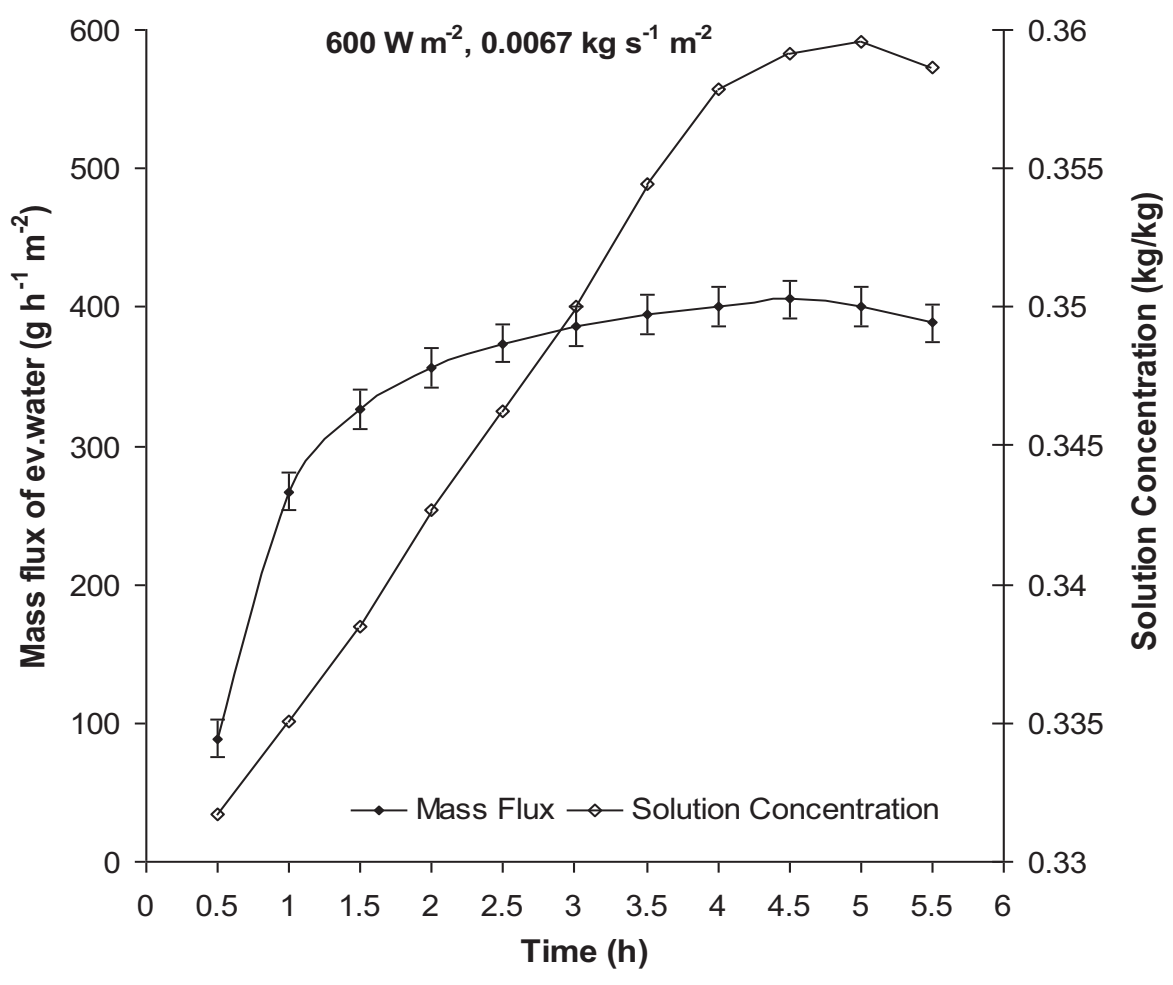

Fig. C2: Mass flux of evaporated water and liquid desiccant concentration at $600 \mathrm{~W}$ $\mathrm{m}^{-2}$ irradiance and $0.0067 \mathrm{~kg} \mathrm{~s}^{-1}$ flow of liquid desiccant per $\mathrm{m}^{2}$ of regenerator. 


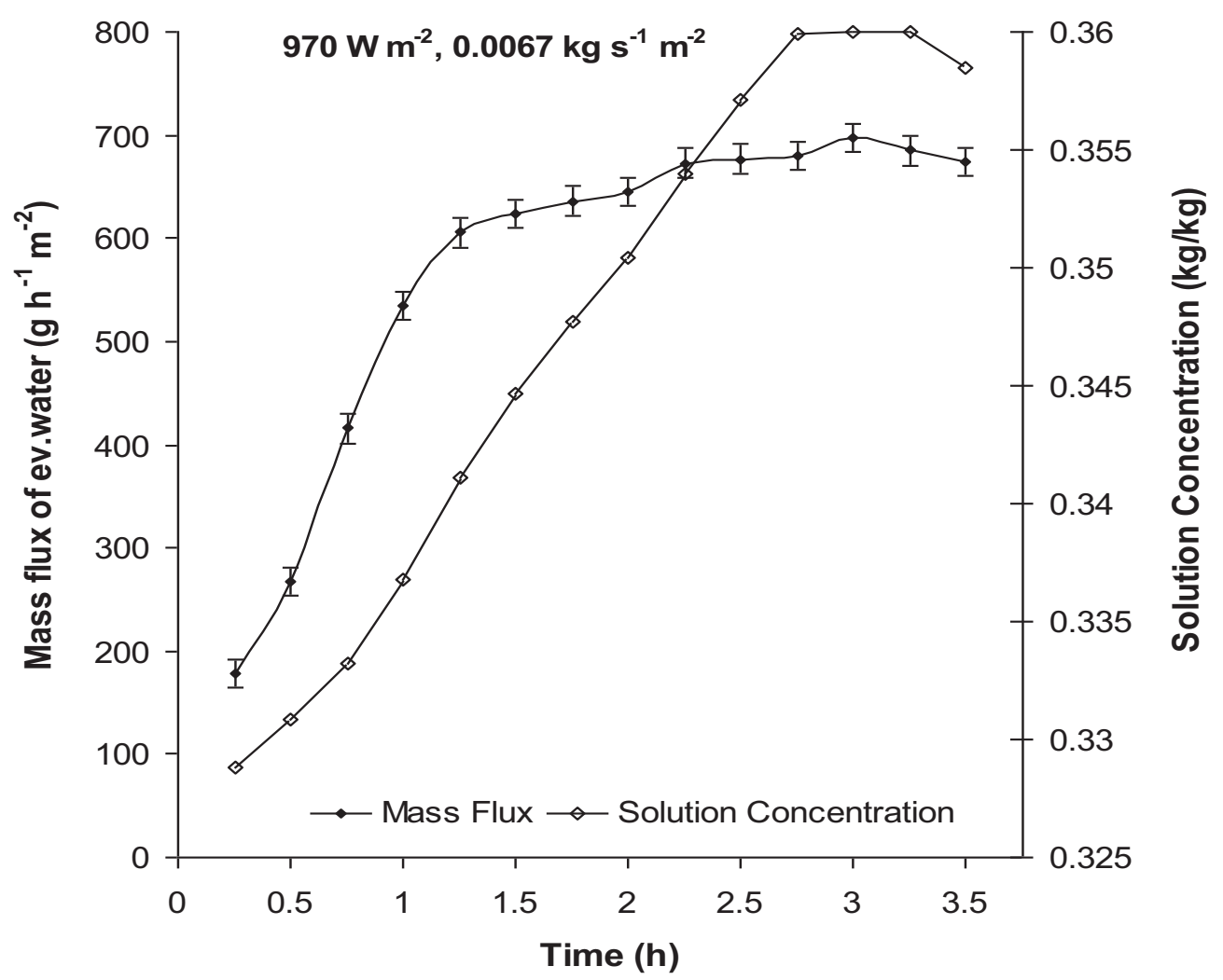

Fig. C3: Mass flux of evaporated water and liquid desiccant concentration at $970 \mathrm{~W}$ $\mathrm{m}^{-2}$ irradiance and $0.0067 \mathrm{~kg} \mathrm{~s}^{-1}$ flow of liquid desiccant per $\mathrm{m}^{2}$ of regenerator.

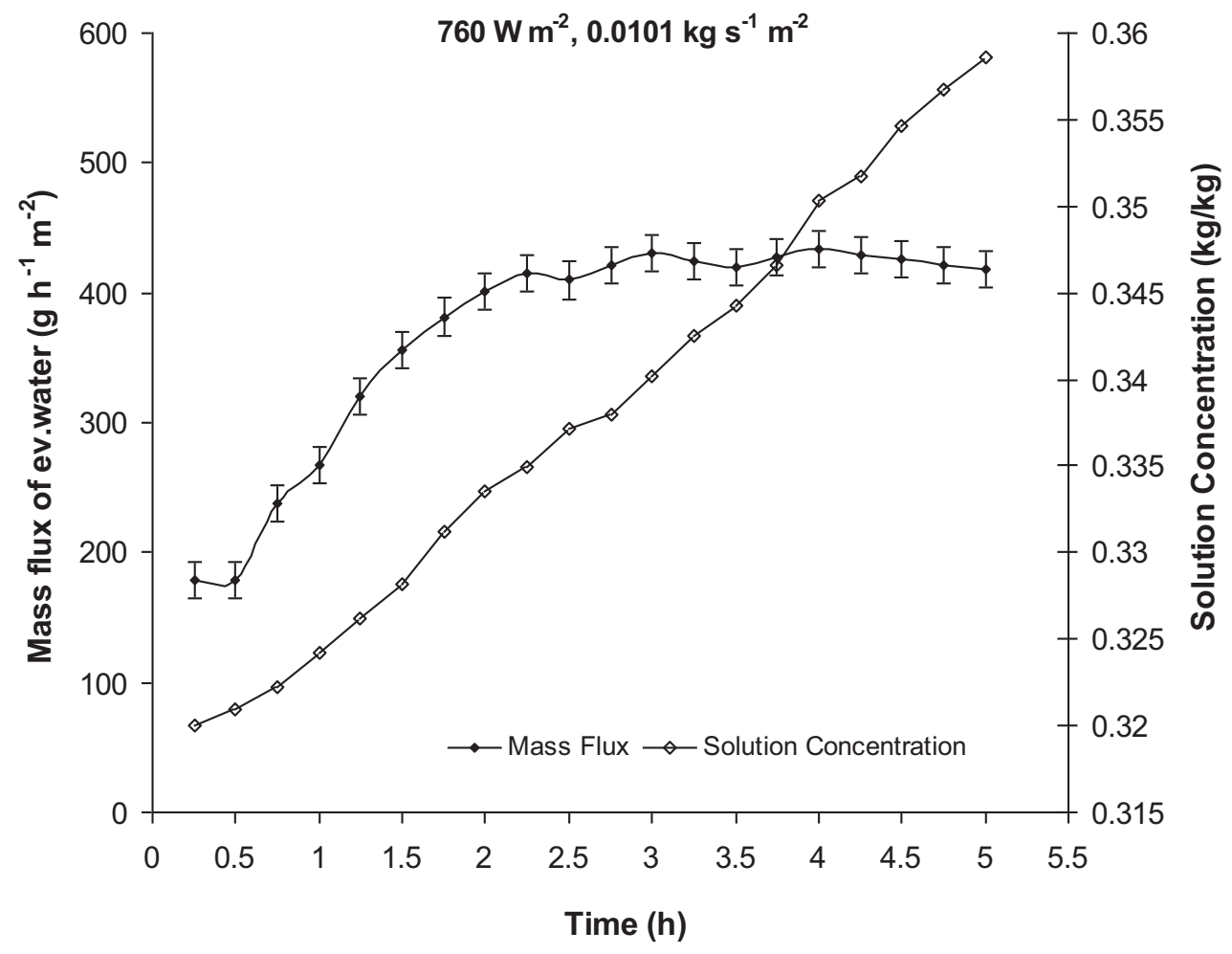

Fig. C4: Mass flux of evaporated water and liquid desiccant concentration at $760 \mathrm{~W}$ $\mathrm{m}^{-2}$ irradiance and $0.0101 \mathrm{~kg} \mathrm{~s}^{-1}$ flow of liquid desiccant per $\mathrm{m}^{2}$ of regenerator. 


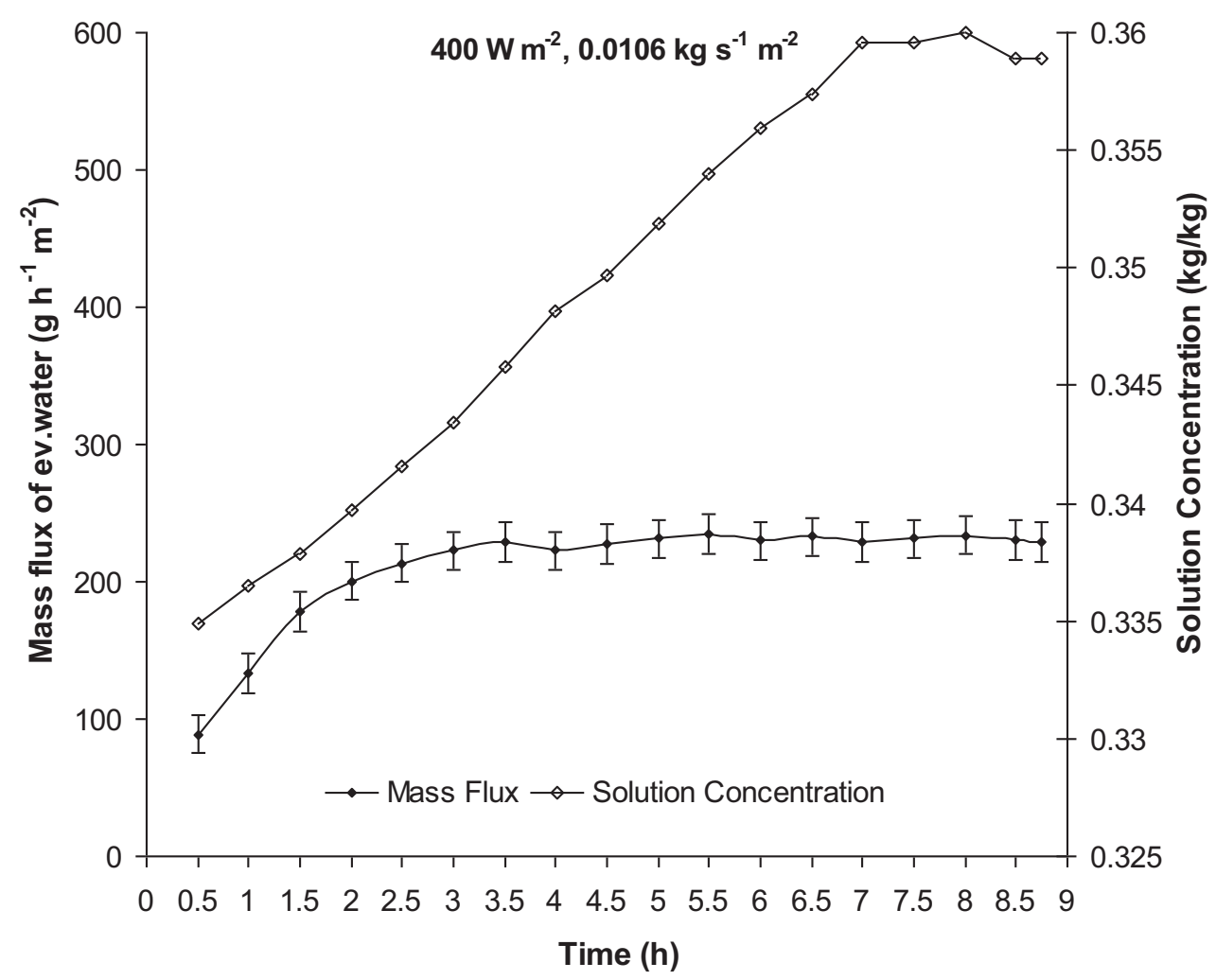

Fig. C5: Mass flux of evaporated water and liquid desiccant concentration at $400 \mathrm{~W}$ $\mathrm{m}^{-2}$ irradiance and $0.0106 \mathrm{~kg} \mathrm{~s}^{-1}$ flow of liquid desiccant per $\mathrm{m}^{2}$ of regenerator.

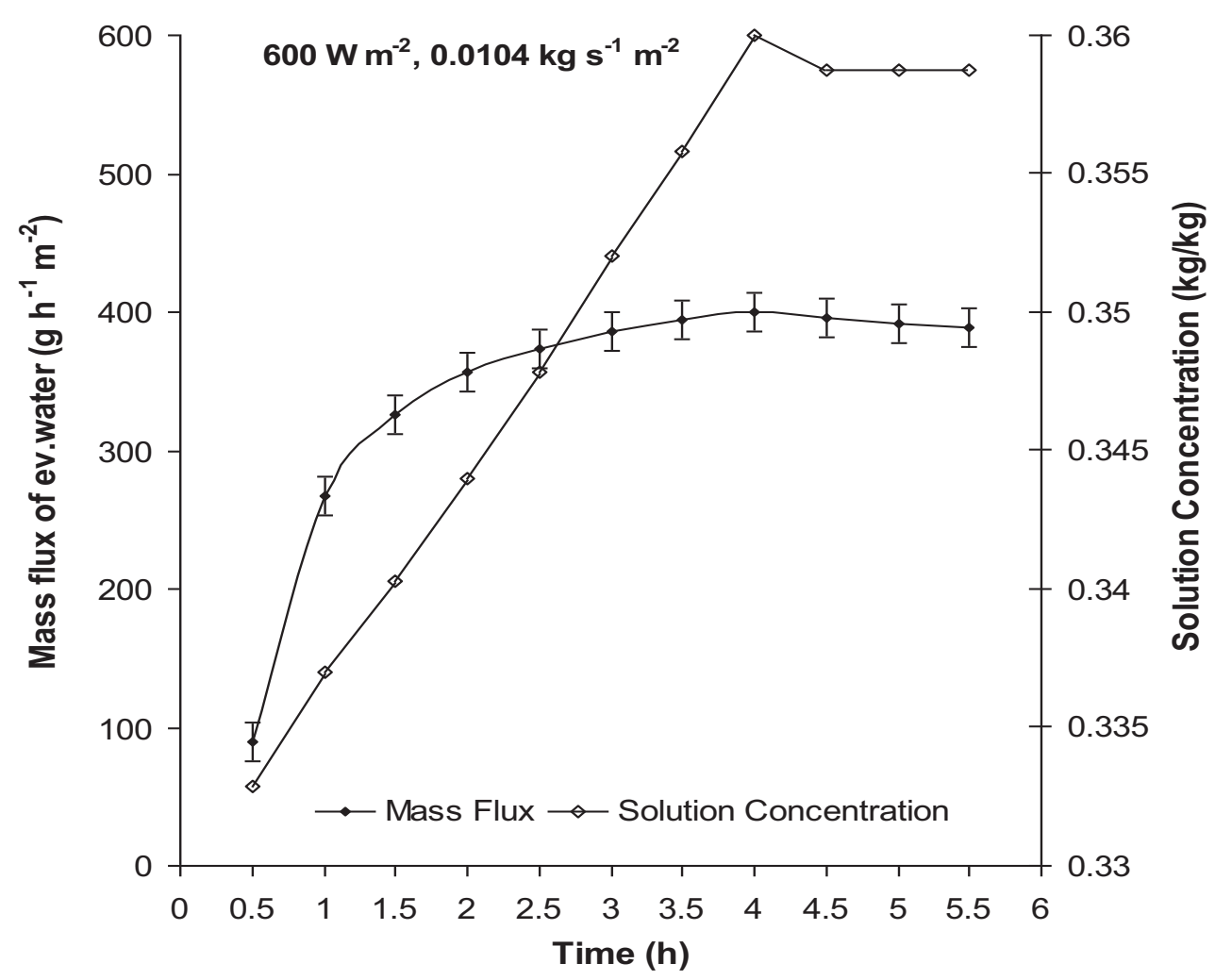

Fig. C6: Mass flux of evaporated water and liquid desiccant concentration at $600 \mathrm{~W}$ $\mathrm{m}^{-2}$ irradiance and $0.0104 \mathrm{~kg} \mathrm{~s}^{-1}$ flow of liquid desiccant per $\mathrm{m}^{2}$ of regenerator. 


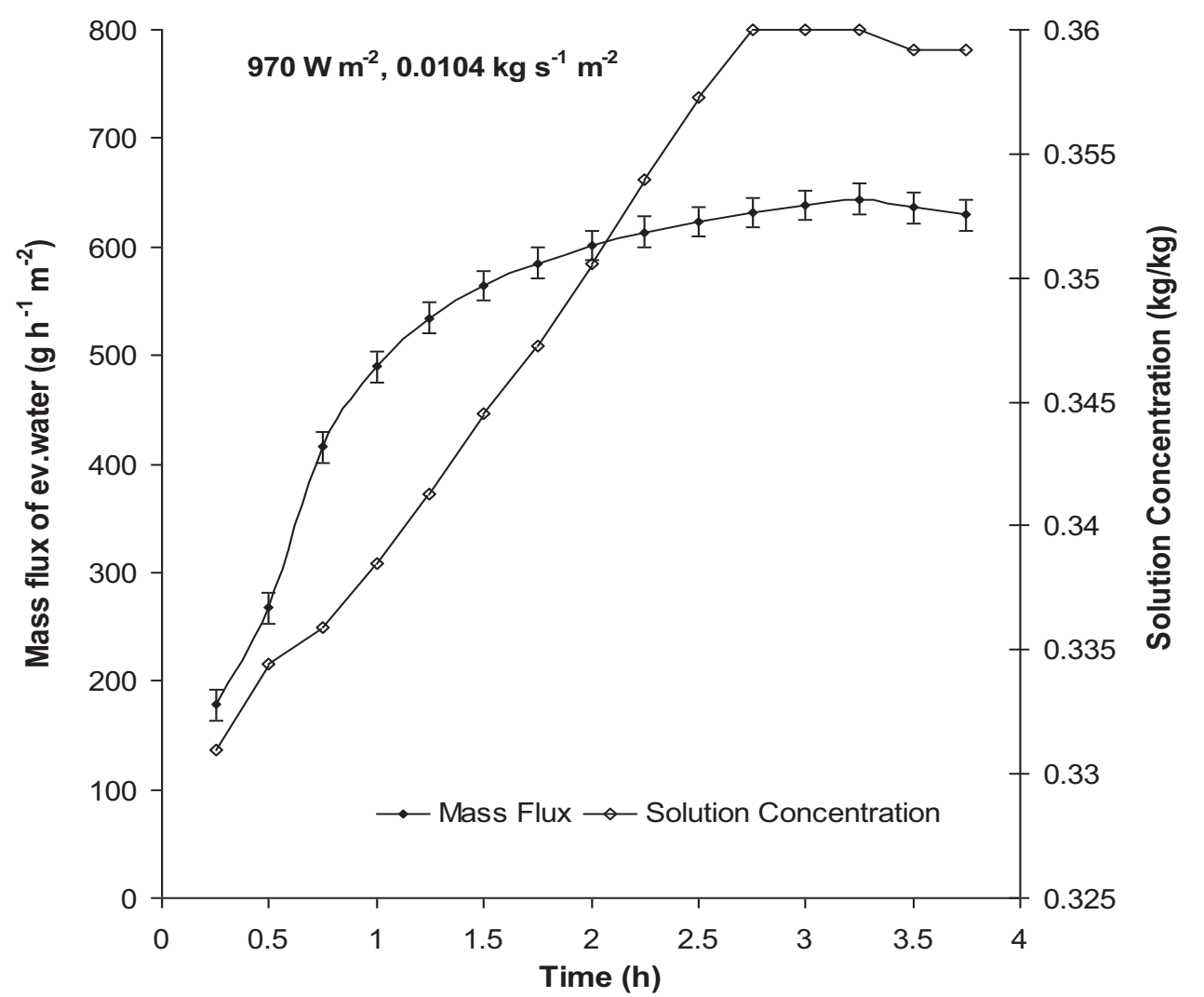

Fig. C7: Mass flux of evaporated water and liquid desiccant concentration at $970 \mathrm{~W}$ $\mathrm{m}^{-2}$ irradiance and $0.0104 \mathrm{~kg} \mathrm{~s}^{-1}$ flow of liquid desiccant per $\mathrm{m}^{2}$ of regenerator. 


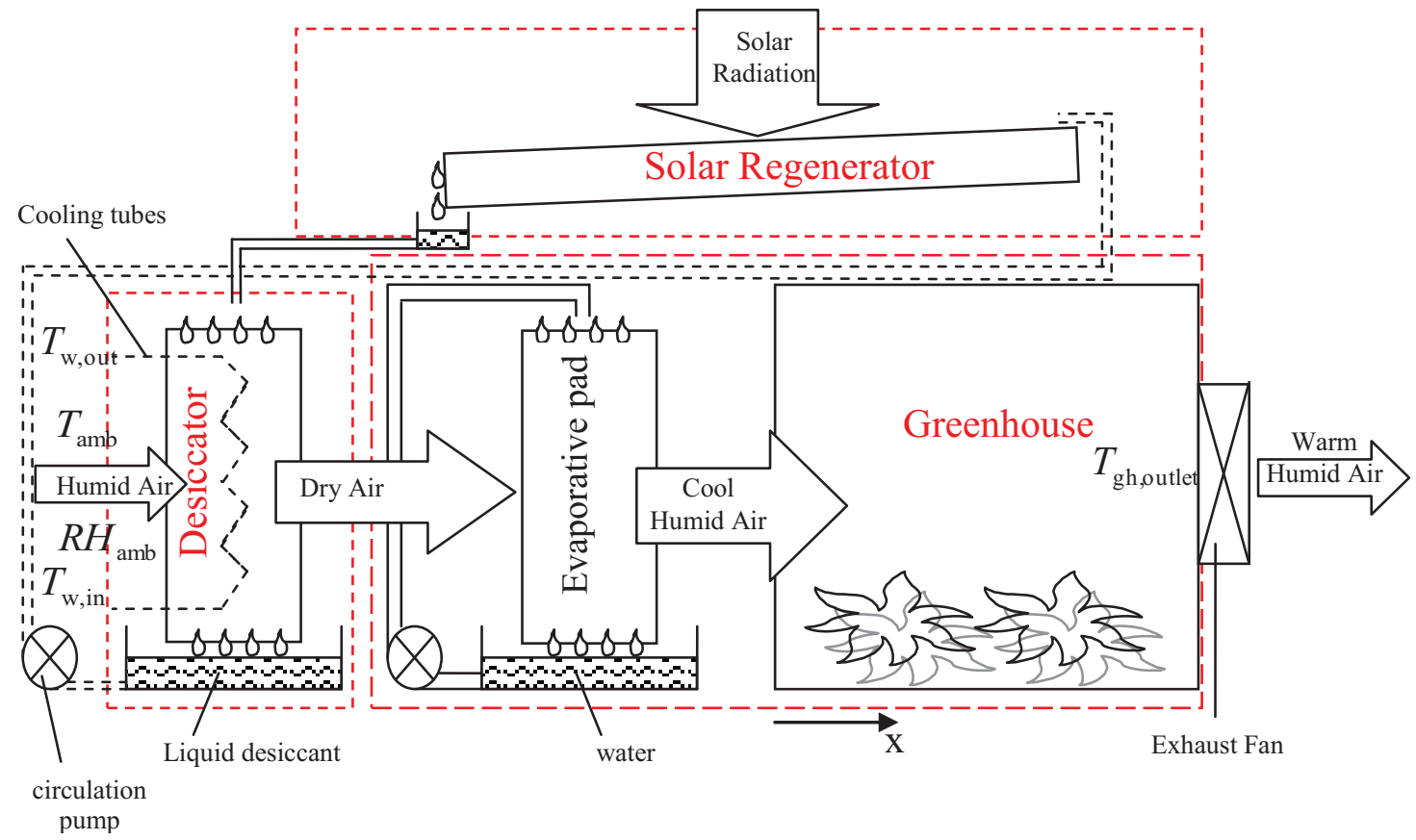

Fig. 1. Schematic of the proposed liquid desiccant cooling system and greenhouse with evaporative pad. The desiccator pad includes cooling tubes, fed with water at the ambient wet bulb temperature $T_{\mathrm{w}, \mathrm{in}}$. 


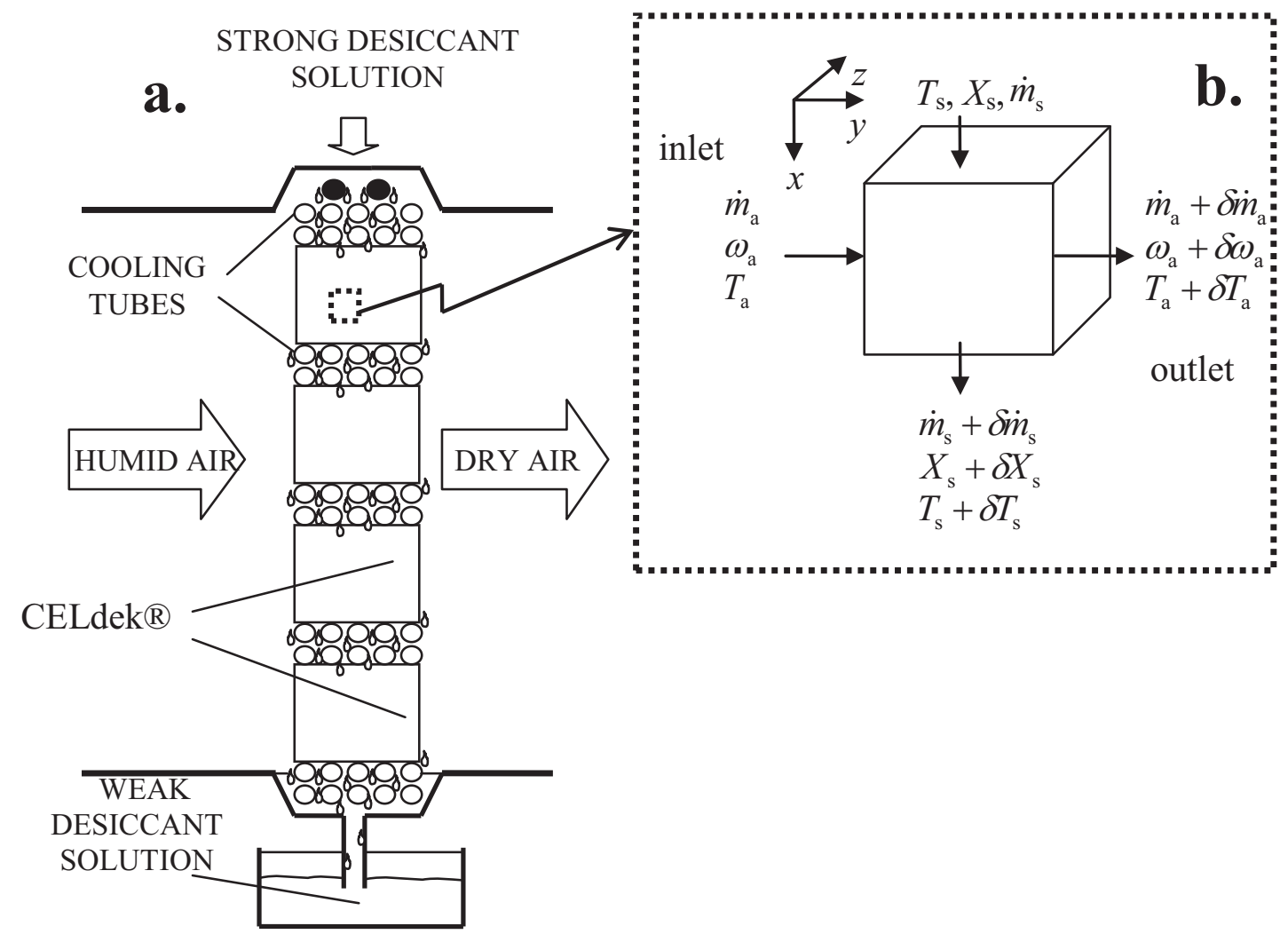

Fig. 2. a) Cross-sectional view of the desiccator and b) a finite control volume within the porous medium (CELdek®). 


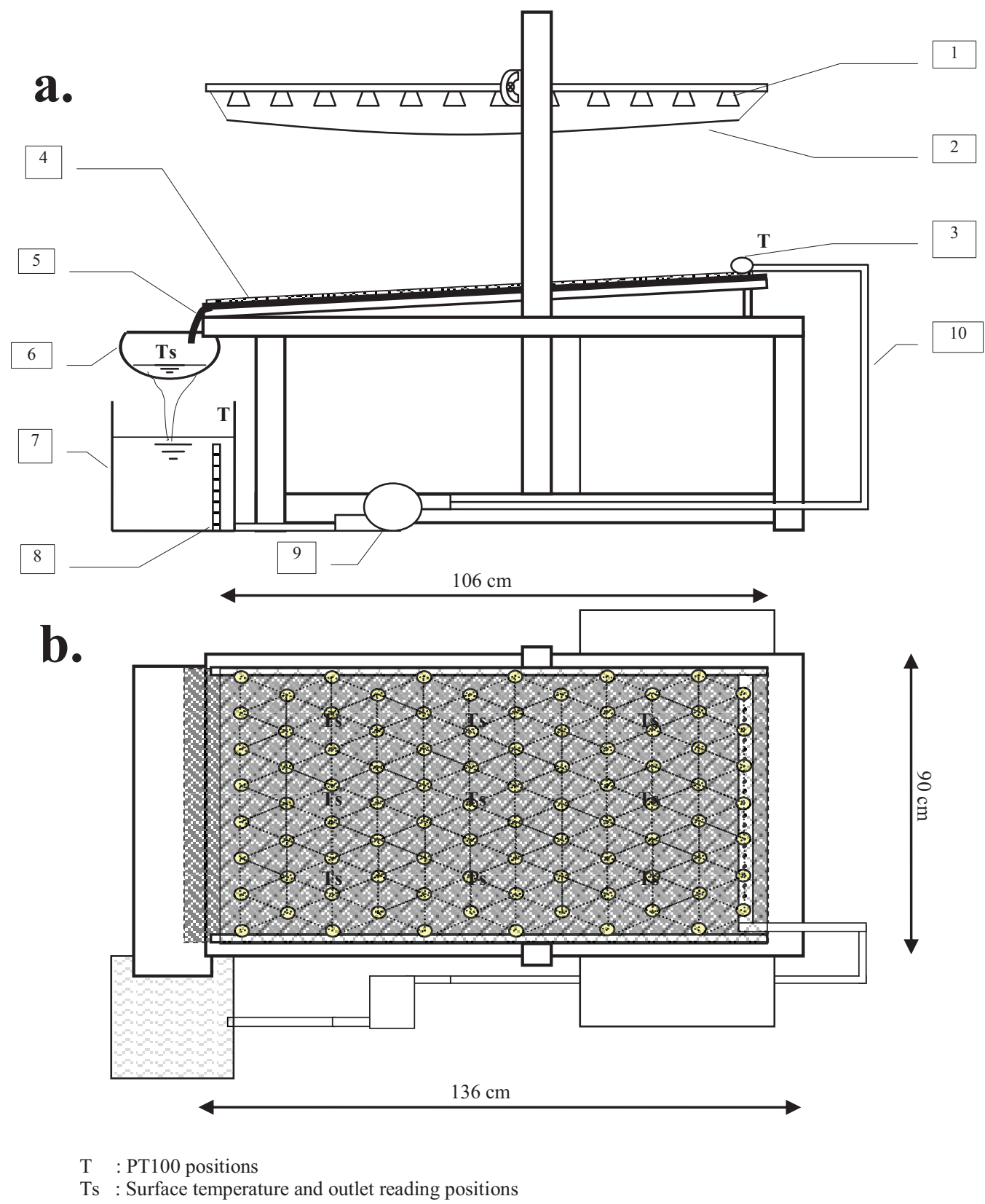

Fig. 3. a) Side view and b) plan view of the regenerator rig. The number tags indicate the following : (1) bulb, (2) diffusion paper, (3) distribution pipe, (4) mulch sheet, (5) neoprene foam sheet, (6) half round gutter, (7) plastic tank, (8) height gauge, (9) peristaltic pump, (10) silicone tubing. 


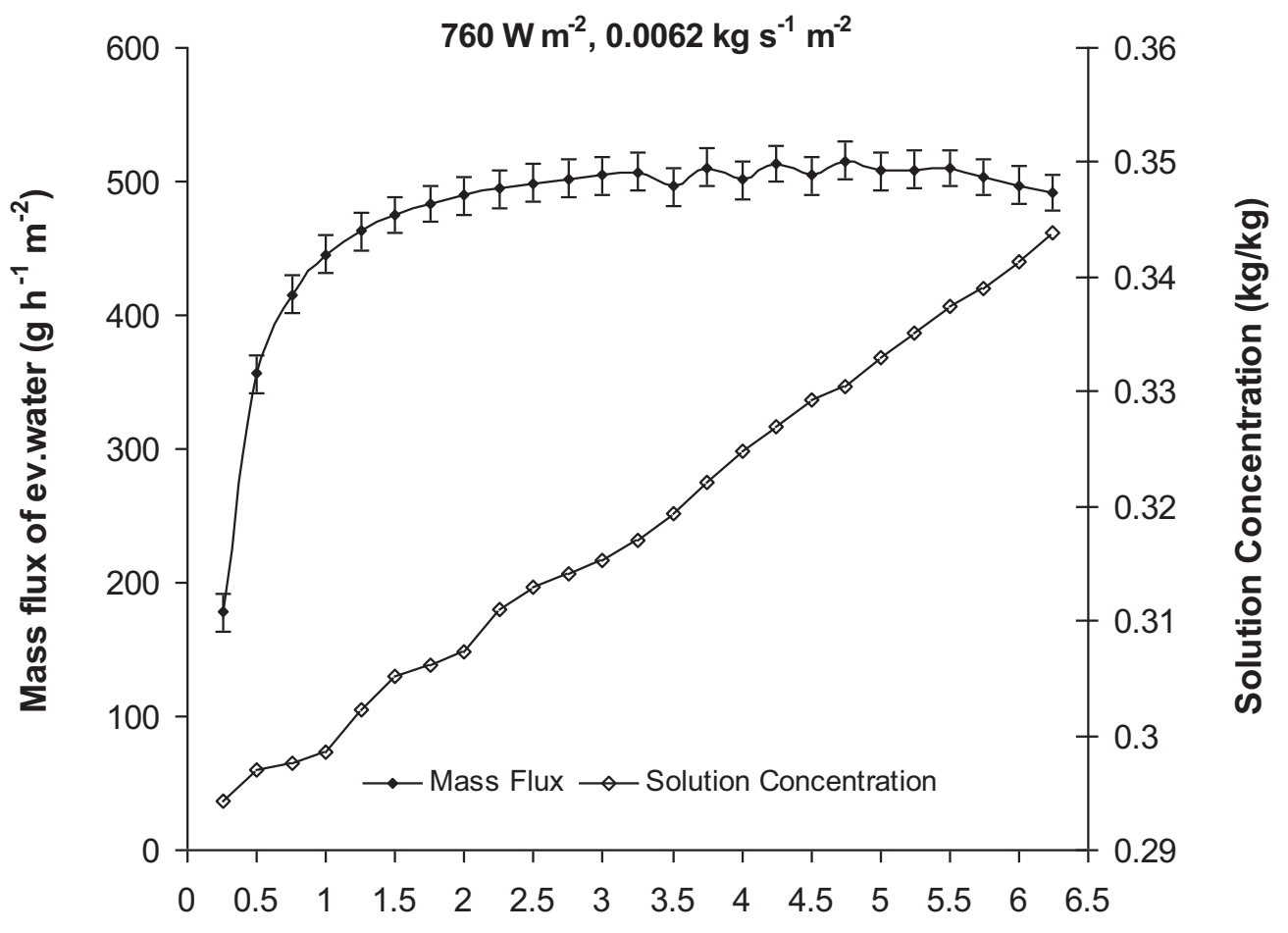

Time (h)

Fig. 4. Experimental measurements from the regenerator. Mass flux of evaporated water and liquid desiccant concentration at $760 \mathrm{~W} \mathrm{~m}^{-2}$ irradiance and $0.0062 \mathrm{~kg} \mathrm{~s}^{-1}$ flow of liquid desiccant per $\mathrm{m}^{2}$ of regenerator. 


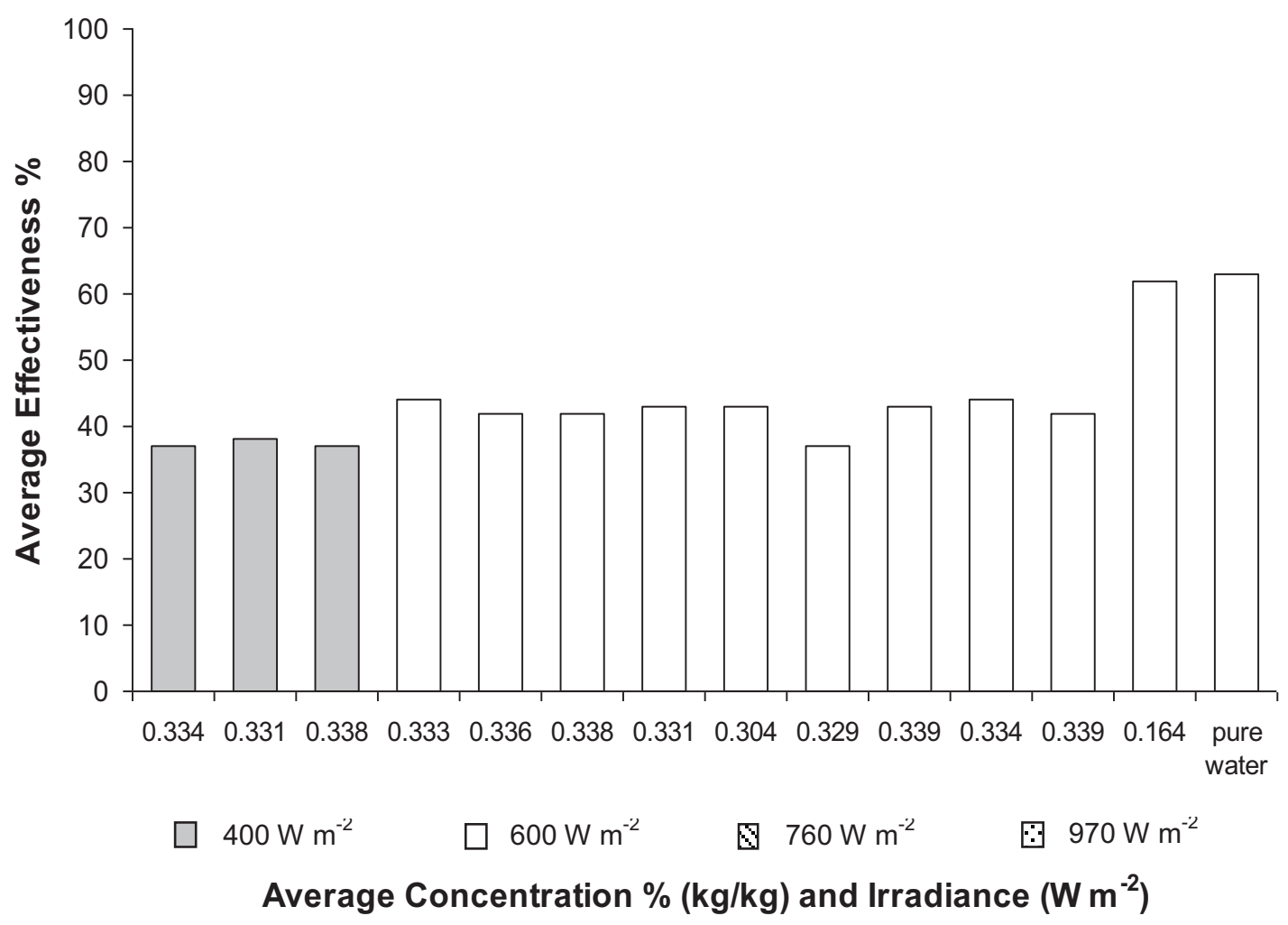

Fig. 5. Average experimental effectiveness of the regenerator at different values of irradiance and liquid desiccant concentration. 


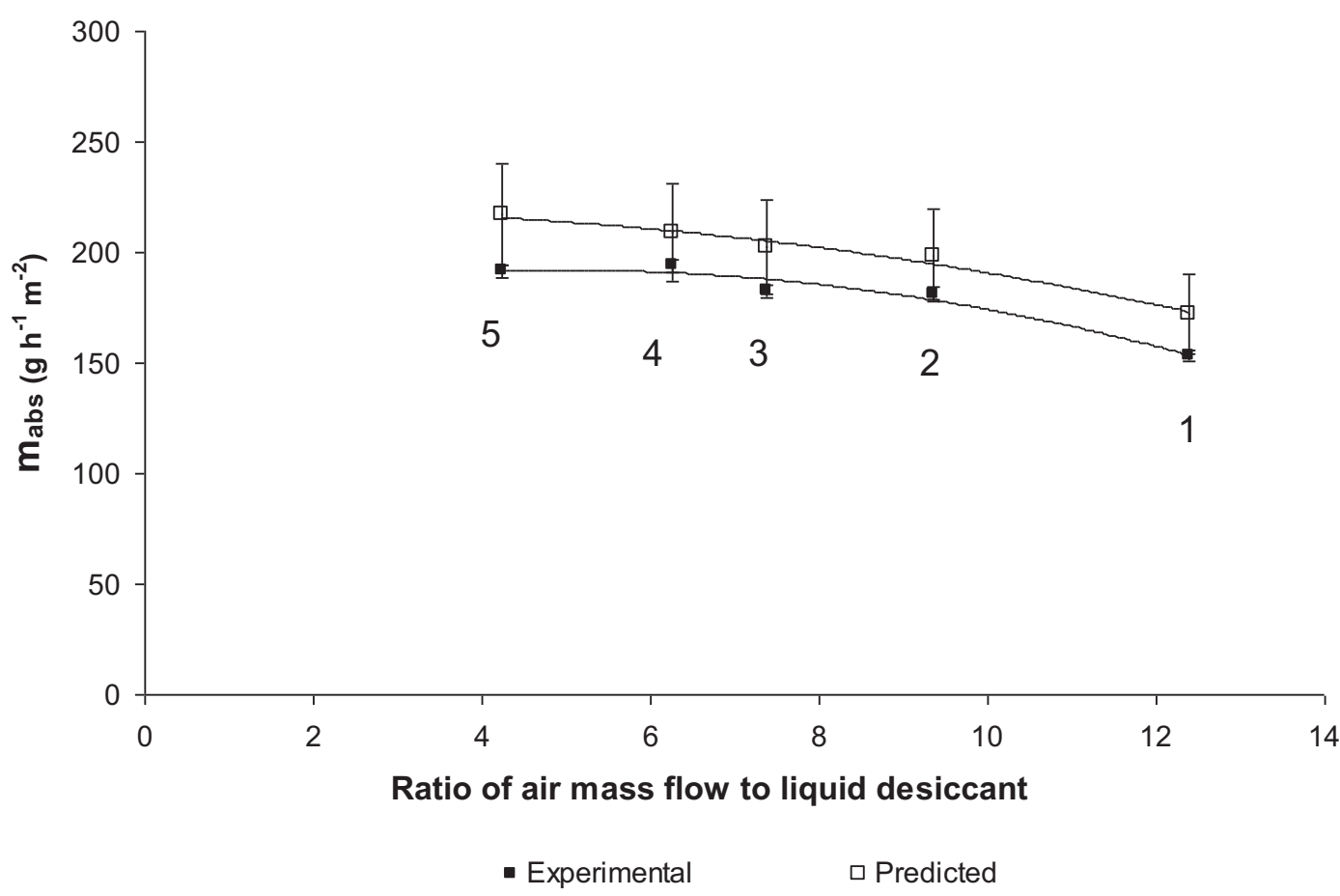

Fig. 6. Desiccator results. Experimental and predicted values of $\dot{m}_{\mathrm{abs}}$ against the ratio of air mass flow to liquid desiccant mass flow. Numbers 1, 2, 3, 4 and 5 indicate the experiments carried out under the conditions shown in table 1. 


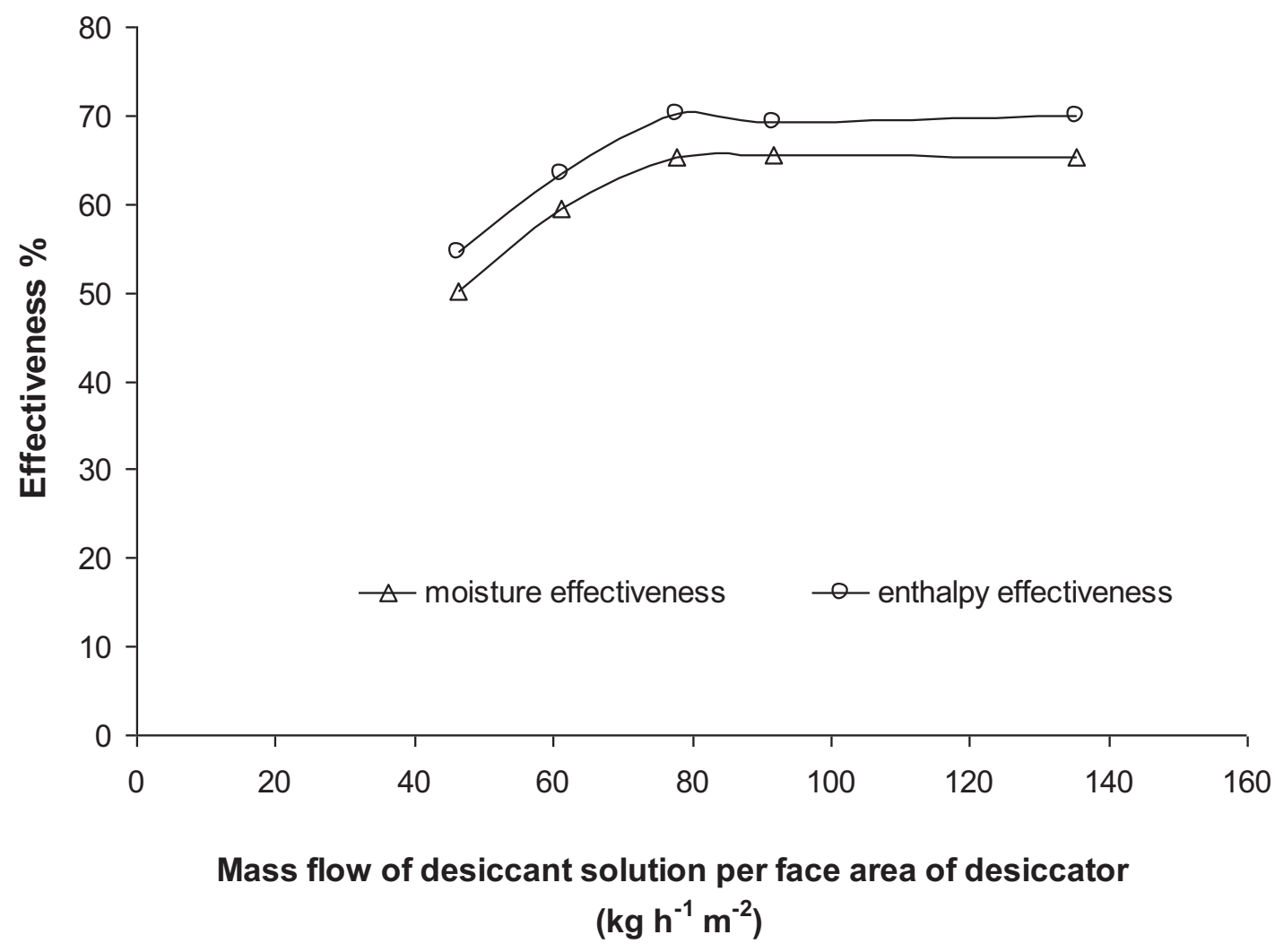

Fig. 7. The calculated experimental enthalpy and moisture effectiveness against the mass flow of the liquid desiccant per face area of desiccator. 


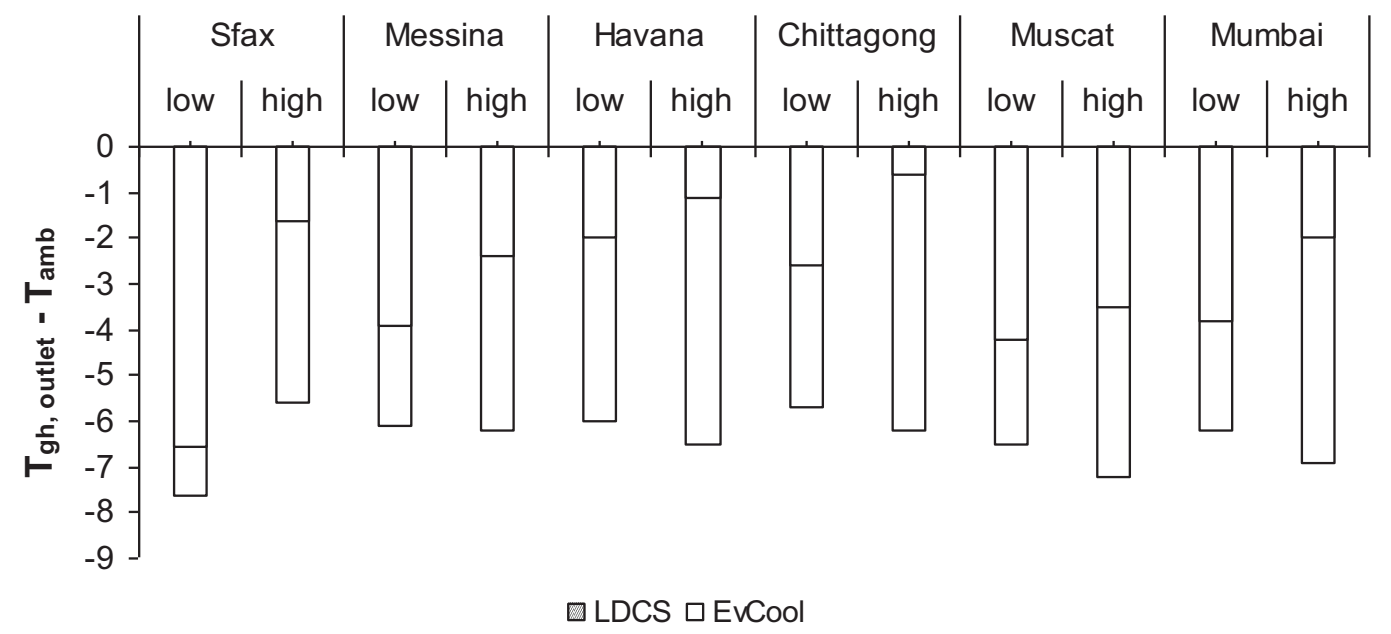

Fig. 8. Temperature decrease predicted with liquid desiccant cooling system (LDCS) compared to evaporative cooling (EvCool) in five cities under dry (low) and humid conditions (high) at the outlet of a $1000 \mathrm{~m}^{2}$. 


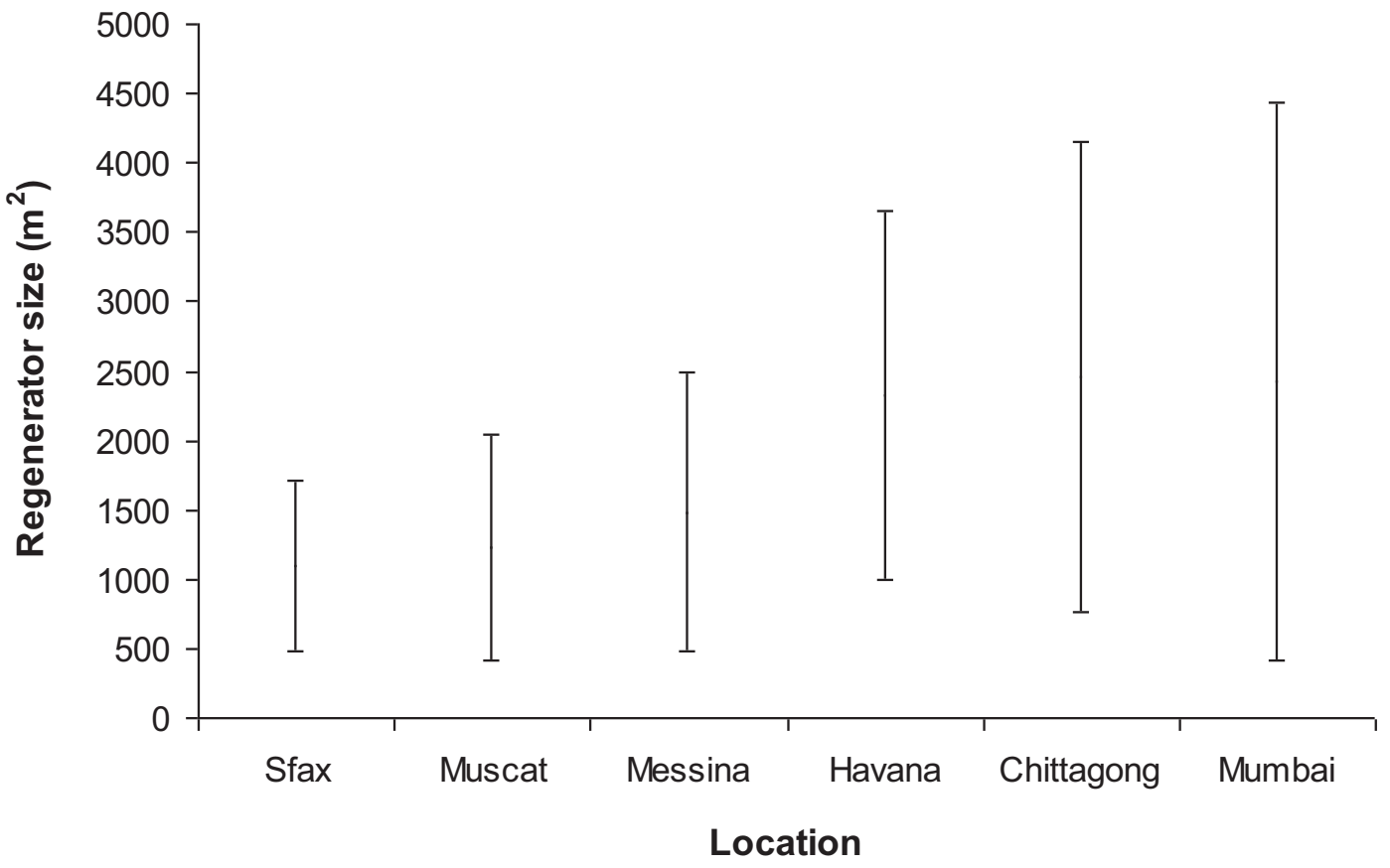

Fig. 9. The predicted regenerator size $\left(\mathrm{m}^{2}\right)$ under the climatic conditions of various locations for a $1000 \mathrm{~m}^{2}$ greenhouse. The ranges indicated by the bars correspond to the varying cooling requirement by month. 


\begin{tabular}{|c|c|c|c|c|c|c|c|c|c|c|c|c|c|c|c|c|c|c|c|}
\hline & \multirow{3}{*}{\multicolumn{3}{|c|}{$\frac{\text { Muscat }}{\text { Month }}$}} & \multirow{3}{*}{\multicolumn{3}{|c|}{$\frac{\text { Havana }}{\text { Month }}$}} & \multirow{3}{*}{\multicolumn{3}{|c|}{$\frac{\text { Messina }}{\text { Month }}$}} & \multirow{3}{*}{\multicolumn{3}{|c|}{$\begin{array}{c}\text { Chittagong } \\
\text { Month }\end{array}$}} & \multirow{3}{*}{\multicolumn{3}{|c|}{$\begin{array}{c}\text { Mumbai } \\
\text { Month }\end{array}$}} & \multirow{3}{*}{\multicolumn{3}{|c|}{$\frac{\text { Sfax }}{\text { Month }}$}} \\
\hline & & & & & & & & & & & & & & & & & & & \\
\hline \multirow{2}{*}{ Crop } & \multirow{2}{*}{$\begin{array}{l}\text { Cooling } \\
\text { system }\end{array}$} & & & & & & & & & & & & & & & & & & \\
\hline & & 5 & 6 & 7 & 7 & 8 & 9 & 7 & 8 & 9 & 4 & 5 & 6 & 3 & 4 & 5 & 7 & 8 & 9 \\
\hline \multirow{2}{*}{ Lettuce } & EvCool & & & & & & & & & & & & & & & & & & \\
\hline & LDCS & & & & & & & & & & & & & & & & & & \\
\hline \multirow{2}{*}{ Tomato } & EvCool & & & & & & & & & & & & & & & & & & \\
\hline & LDCS & & & & & & & & & & & & & & & & & & \\
\hline \multirow{2}{*}{ Cucumber } & EvCool & & & & & & & & & & & & & & & & & & \\
\hline & LDCS & & & & & & & & & & & & & & & & & & \\
\hline \multirow{2}{*}{$\begin{array}{l}\text { Soya } \\
\text { bean }\end{array}$} & EvCool & & & & & & & & & & & & & & & & & & \\
\hline & LDCS & & & & & & & & & & & & & & & & & & \\
\hline
\end{tabular}

Temperatures too high, growing difficult or non - viable Temperatures higher than optimum but growing possible Optimal temperatures for growing

Temperatures lower than optimum but growing possible

Fig. 10. Comparison of liquid desiccant (LDCS) and evaporative cooling (EvCool) systems when applied to a $1000 \mathrm{~m}^{2}$ greenhouse for growing lettuce, tomato, cucumber and soya bean during the hot season for each location. 
Table 1. Experimental inlet conditions for the desiccator, used in the verification of the theoretical model.

\begin{tabular}{|c|c|c|c|c|c|c|c|}
\hline \multirow{2}{*}{ Exp } & Air Temp. & $\begin{array}{c}\text { Liquid desiccant } \\
\text { Temp }\end{array}$ & $\begin{array}{c}\text { Cooling water } \\
\text { Temp. }\end{array}$ & $\mathrm{RH}$ & $\begin{array}{c}\text { Liquid desiccant } \\
\text { Concentration }\end{array}$ & $\begin{array}{c}\text { Mass flow } \\
\text { of air }\end{array}$ & $\begin{array}{c}\text { Mass flow } \\
\text { of desiccant }\end{array}$ \\
\cline { 2 - 7 } & ${ }^{\circ} \mathrm{C}$ & ${ }^{\circ} \mathrm{C}$ & ${ }^{\circ} \mathrm{C}$ & $\%$ & $\mathrm{~kg} \mathrm{~kg}^{-1}$ & $\mathrm{~kg} \mathrm{~s}^{-1}$ & $\mathrm{~kg} \mathrm{~s}^{-1}$ \\
\hline 1 & 34.7 & 29.2 & 18.3 & 69.1 & 0.3568 & 0.0263 & 0.0021 \\
\hline 2 & 34.9 & 33.7 & 17.9 & 70.6 & 0.3481 & 0.0263 & 0.0028 \\
\hline 3 & 34.7 & 30.3 & 15.3 & 66.8 & 0.3414 & 0.0263 & 0.0036 \\
\hline 4 & 35.2 & 31.2 & 18.4 & 69.5 & 0.3446 & 0.0263 & 0.0042 \\
\hline 5 & 35.2 & 31.8 & 16.8 & 67.1 & 0.3439 & 0.0263 & 0.0062 \\
\hline
\end{tabular}


Table 2. The predicted and experimental values of the regenerator effectiveness with the relative errors at various irradiance levels and mass fluxes of liquid desiccant.

\begin{tabular}{|c|c|c|c|c|}
\hline \multirow{3}{*}{ Irradiance } & $\begin{array}{c}\text { Mass Flux of } \\
\text { liquid } \\
\text { desiccant } \\
\left(\mathrm{W} \mathrm{m}^{-2}\right)\end{array}$ & \multicolumn{2}{|c|}{ Effectiveness } & Relative \\
\cline { 2 - 5 }$\left(\mathrm{kg} \mathrm{s}^{-1} \mathrm{~m}^{-2}\right)$ & $\begin{array}{c}\text { Predicted } \\
\%\end{array}$ & $\begin{array}{c}\text { Experimental } \\
\%\end{array}$ & $\begin{array}{c}\text { Error } \\
\%\end{array}$ \\
\hline \multirow{3}{*}{400} & 0.0034 & 38 & 37 & 0.6 \\
\cline { 2 - 5 } & 0.006 & 40 & 38 & 6.5 \\
\cline { 2 - 5 } & 0.0106 & 38 & 37 & 2.5 \\
\hline \multirow{3}{*}{600} & 0.0033 & 47 & 46 & 2.7 \\
\cline { 2 - 5 } & 0.0067 & 43 & 42 & 2.5 \\
\cline { 2 - 5 } & 0.0104 & 44 & 42 & 4.4 \\
\hline \multirow{3}{*}{760} & 0.0031 & 45 & 43 & 3.5 \\
\cline { 2 - 5 } & 0.0062 & 43 & 43 & 0.2 \\
\cline { 2 - 5 } & 0.0101 & 37 & 36 & 1.0 \\
\hline \multirow{3}{*}{970} & 0.0033 & 42 & 42 & 1.1 \\
\cline { 2 - 5 } & 0.0067 & 46 & 43 & 6.9 \\
\cline { 2 - 5 } & 0.0104 & 42 & 41 & 2.0 \\
\hline
\end{tabular}


Table 3. The parameters used for the model predictions. Regenerator size was as shown by Fig.9.

\begin{tabular}{|l|l|}
\hline Parameter & Value \\
\hline Greenhouse plan area & $1000 \mathrm{~m}^{2}$ \\
\hline Thickness of desiccator & $0.2 \mathrm{~m}$ \\
\hline Height of desiccator & $1.11 \mathrm{~m}$ \\
\hline Thickness of evap. pad & $0.1 \mathrm{~m}$ \\
\hline $\begin{array}{l}\text { No of tubes per tube bundle } \\
\text { (height interval 0.1 m) }\end{array}$ & 20 \\
\hline Specific volumetric flow rate of air* & $5.03 \times 10^{-4} \mathrm{~m}^{3} \mathrm{~s}^{-1} \mathrm{~m}^{-2}$ \\
\hline Specific mass flow rate of liquid desiccant & $9.00 \times 10^{-3} \mathrm{~kg} \mathrm{~s}^{-1} \mathrm{~m}^{-2}$ \\
\hline Specific mass flow rate of cooling water* & $0.335 \mathrm{~kg} \mathrm{~s}^{-1} \mathrm{~m}^{-2}$ \\
\hline \multirow{}{*}{ per face area of the desiccator } & \\
\hline
\end{tabular}

per face area of the desiccator 
Table 4. Growing temperatures for four different crops $\left({ }^{\circ} \mathrm{C}\right)$.

\begin{tabular}{|l|c|c|c|c|}
\hline Crop & Minimum & \multicolumn{2}{|c|}{ Optimum range } & Maximum \\
\hline Lettuce $^{\mathrm{a}}$ & 7 & 17 & 23 & 28 \\
\hline Tomato $^{\mathrm{a}}$ & 17 & 27 & 29 & 32 \\
\hline Cucumber $^{\mathrm{a}}$ & 18 & 27 & 29 & 35 \\
\hline Soya bean $^{\mathrm{b}}$ & 20 & 25 & 30 & 40 \\
\hline
\end{tabular}

${ }^{\mathrm{a}}$ From ref [4]

${ }^{\mathrm{b}}$ Form ref [63] 
Table 5. Comparison of the model accuracy in predicting enthalpy and moisture effectiveness against similar published studies of desiccators using cellulose structured packing, showing also the main experimental parameters.

\begin{tabular}{|r|c|c|c|}
\hline Experimental parameters & This study & $\begin{array}{c}\text { Liu et al } \\
{[52]}\end{array}$ & $\begin{array}{c}\text { Moon et } \\
\text { al [25] }\end{array}$ \\
\hline Type of liquid desiccant & $\mathrm{MgCl}_{2}$ & $\mathrm{LiBr}$ & $\mathrm{CaCl}_{2}$ \\
\hline Air inlet temperature $\left({ }^{\circ} \mathrm{C}\right)$ & $34.7-35.2$ & $24.7-35.4$ & 31.7 \\
\hline Air inlet absolute humidity $(\mathrm{kg} / \mathrm{kg})$ & $0.016-0.027$ & $0.010-0.021$ & 0.02157 \\
\hline $\mathrm{ERH}$ of liquid desiccant $(\%)$ & $32-39$ & $17-41$ & 33 \\
\hline Accuracy of model prediction & & & \\
\hline \% error in enthalpy effectiveness & \pm 8 & \pm 8 & n.a. \\
\hline \% error in moisture effectiveness & \pm 8 & \pm 8 & \pm 10 \\
\hline
\end{tabular}

